\title{
Closed-cycle Textile Dyeing: Full-scale Hyperfiltration Demonstration (Design)
}

by

LaFrance Industries

La France, South Carolina 29656

DISCLAIMER CARRE, Inc.

Seneca, South Carolina. 29678

EPA Grant No. $\$ 805182$

EPA Program Element No. 1 BB610

DOE Project Officer: William Sonnett

DOI Project Officer: Frank Coley

EPA/IERL-Cin Technical Advisor: Robert Mournighan

EPAVIERL-RTP Project Officer: Robert Hendriks

Industrial Environmental Research Laboratory

Office of Environmental Engineering and Technology

Research Triangle Park. NC 27711

\section{Prepared for}

U.S. Department of Energy Industrial Programs

Washington, DC 20585
U.S. Department of the Interior Office of Water Research and Technology Washington, DC 20240

U.S. Environmental Protection Agency

Office of Research and Development Washington, DC 20460

\section{NOTICE}

PORTIOUSS OF THIS REPOR: AME IIIEGIBLE.

It has bean reproducod fron the hest available copy to permil the braodiest possible availability. 


\section{DISCLAIMER}

This report was prepared as an account of work sponsored by an agency of the United States Government. Neither the United States Government nor any agency Thereof, nor any of their employees, makes any warranty, express or implied, or assumes any legal liability or responsibility for the accuracy, completeness, or usefulness of any information, apparatus, product, or process disclosed, or represents that its use would not infringe privately owned rights. Reference herein to any specific commercial product, process, or service by trade name, trademark, manufacturer, or otherwise does not necessarily constitute or imply its endorsement, recommendation, or favoring by the United States Government or any agency thereof. The views and opinions of authors expressed herein do not necessarily state or reflect those of the United States Government or any agency thereof. 


\section{DISCLAIMER}

Portions of this document may be illegible in electronic image products. Images are produced from the best available original document. 
Hyperfiltration (HF) is a membrane separation technique that has been used successfully in desalination of natural water. Because energy, process chemicals and water are discharged from industrial processes in large quantities, the application of various types of membranes to recover through recycle has been studied in a series of government sponsored research projects. The results of the research led to the current project of joining a full scale dynamic membrane HF system with an operating dye range into an integrated production unit. The dye range is a multi-purpose unit having a variety of effluents from preparation and dyeing of textile fabric.

On site pilot scale tests of three membrane types led to the selection of the dynamic membranes on porous sintered stainless steel tubular supports. Also the testing led to conversion of the washing to counterflow thereby reducing the water use from $400 \mathrm{~m}^{3} / \mathrm{d}(75 \mathrm{gpm})$ to $190 \mathrm{~m} / \mathrm{d}$ ( $35 \mathrm{gpm}$ ) without any loss in effectiveness. Water recycle, up to $95 \%$ of waste water, is now routinely used. Over a million meters of fabric have been produced with recycle water. Two 4000 meters lots of fabric have been produced with the recycled chemical concentrate.

The project developed capital and operating costs and savings for one year of operation. A payout time of 3.5 years will be realized when chemical recovery is fully implemented and membrane washing procedures are better developed. Both these areas will be further developed during an extension of this project to September, 1983.

The results of this demonstration and other related information has shown that an $H F$ recovery system will yield a payout time in the range of one to five years in situations where there are simultaneous benefits for water, energy, and chemical recovery and/or where significant waste treatment costs can be abated.

This report describes the design and construction of the hyperfiltration equipment; presents and evaluates data from one year of operation; gives costs for equipment, installation and operation, and credits for savings due to recycle; and describes the primary objectives of an 18 month project continuation. 
Hyperfiltration (reverse osmosis) is a membrane separation technique it has been used effectively in desalination of seawater. Successful salination membranes were not applicable in many cases to the more harsh industrial effluents. Because expensive energy, process chemicals and water are used in industrial processes and then are discharged, the application of membranes to recover water, energy, and process chemicals was studied in $a$ series of government sponsored research projects. The results of the research led to the current project of joining a full scale dynamic membrane hyperfiltration (HF) system with an operating dye range to produce an integrated unit. The dye range is a multi-purpose machine having a variety of effluents presenting a good test situation for demonstrating HF recovery equipment on industrial process effluents. The equipment has been in operation for over twelve months and recycled water is now routinely used. Laboratory tests of the dye and auxiliary chemicals reused have been completed and an initial full scale reuse of chemicals has been tested.

\section{RANGE PROCESS AND EFFLUENT CHARACTERISTICS}

The dye range is used for dyeing, bleaching and scouring a variety of velour fabrics. The range operates three shifts per day, five to seven days per week, at speeds of 9 to $36 \mathrm{~m} / \mathrm{min}$ selected as required by the process. Cotton, acrylic, nylon, rayon, polyester fabrics and their blends are processed. Although several classes of dyes are used, (i.e., direct, basic, disperse, acid, and reactive) and the wash water effluent components vary in dye type and concentration, the types of auxiliary chemicals are common to all wash water effluents from the dyeing operations. The dye formulations contain dyes, a thickener, surfactants, and in some cases dye solvents. While about $85 \%$ of the dyes are exhausted on the fabric, the remaining dye and most of the auxiliary chemicals are removed by the washing process. An important part of the project was the successful reduction of the flow rate of wash water through the range by converting to counterflow and using higher temperatures. The resulting wash water flow was reduced from about 400 $\mathrm{m}^{3} / \mathrm{d}(75 \mathrm{gpm})$ to about $190 \mathrm{~m} / \mathrm{d}(35 \mathrm{gpm})$ without loss of washing effectiveness.

\section{RECOVERY PROCESS}

The wash water is collected continuously. Despite the lapse of time between each production lot, for cleaning the equipment and filling the dye pad, the water flow is continued to reduce the color in the water in the washers (by about $30 \%$ ). The washing section effluent (HF supply) is usually highly colored. Removal of $97 \%$ of the dyes is considered necessary to avoid possible staining of the fabric subjected to recycled water. The auxiliary components must also be removed sufficiently to provide wash water with concentration differences suitable for the effective washing of the 
fạbricn:

The concentrate produced by the HF unit contains dye concentrations much lower than those in the dye pad solution, but comparible concentrations of auxiliary chemicals. Reuse of the $\mathrm{HF}$ concentrates in dye formulation is sible with approximately $75 \%$ savings in auxiliary chemicals and about $20 \%$ savings in dyes depending upon the dye class. Effective reuse of the residual dyes and auxiliary chemicals in the $H F$ concentrate depends on the ability to add dyes to achieve the required shades, hue, and crocking characteristics needed in production. Reuse of the HF concentrate can be enhanced by judicious scheduling of dyeing lots, as to shade and dye class. To this end, appropriate scheduling has been suggested and initiated, but is often interrupted by production demands. Two 4,000 meter lots of fabrics have been produced using recovered auxiliary chemicals.

HF UNIT DESCRIPTION

Range wash water is supplied at a rate of $190 \mathrm{~m}^{3} / \mathrm{d}$ (35 gpm) and collected during the dyeing runs in the $23 \mathrm{~m}^{3}(6,000$ gallonş) accumulator tank. The permeate storage (rinse water) tanks is also $23 \mathrm{~m}^{3}$ to prevent overflow from the system.

The HF unit is a Single Pass (patented) system consisting of zirconium oxide-polyacrylic (ZOPA) membranes dynamically formed on the interior of 70 sintered stainless steel support tube bundles, arranged in ten modules. The total membrane area is $139 \mathrm{~m}^{3}\left(1,500 \mathrm{ft} .{ }^{2}\right)$ pressurized by a positive displacement pump fed from the wastewater tank. The concentrate varies to a set upper limit at which an automatic bypass valve bleeds feed to the pump section reducing the feed flow to the th unit.

There is also a $0.75 \mathrm{~m}^{3}$ (200 gallon) tank following the accumulator tank which permits circulation of a solution for cleaning the membranes.

\section{HF PERFORMANCE}

The HF unit was designed from pilot test data to treat wash water at a process temperature of $85^{\circ} \mathrm{C}$ with color removal of at least $97 \%$ at high volumetric recycle.

Installation of the UF unit was completed May 1, 1981. For about one year the HF unit performance, recycle efficiency, range product quality, ald economic evaluation have been monitored. The HF unit is used routinely for full scale permeate recycle. Regenerative heat exchangers have been installed to allow operation of the $\mathrm{HF}$ at $85-95^{\circ} \mathrm{C}$ while the range effluent temperature is varied from $55-85^{\circ} \mathrm{C}$. A maximum inlet pressure of about 8.5 MPa ( $1,230 \mathrm{psig})$ is being used. Recoveries of from 85-95\% are being used depending on range speed to return $H F$ concentrate at dye pad strength. 


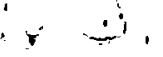

Over a million meters of fabric have been produced with recycle water. There has been no adverse effect on fabric quality as determined by the normal production quality control. Some permeate from very concentrated dye rmulations are considered by the range operator and rejected for reuse. In e case cross staining occurred when the dye concentration ratio between consecutive production lots was over 100 to 1 . Two lots of 4,000 meters each have been produced with HF concentrate plus dye additives to match the production shade for each lot.

Extensive membrane fouling has been experienced. In the attempts to remove the various foulants, washing has involved the use of detergents and emulsifiers to remove silicones (antifoams), enzymes to remove carbohydrates (undissolved guar gum, the dye thickener), acetic acid and citric acid at $\mathrm{pH}$ - 4 to remove hard water scaling and dye solvents to remove deposited dye particles and precipitates of the reaction of basic and direct dyes.

Design capacity of the unit would enable completely closed cycle operation, and in fact, the BF unit has equaled $150 \%$ of the requirements immediately after each cleaning of the membranes. Membrane fouling, however, has limited the average production of the HF unit to about $60 \%$ of the capacity required for a complete closed cycle operation. The problem of membrane fouling (which will be the subject of continued investigation during the extension of the project) may be solved by one or more of three methods of approach: (1) a modification of frequency and duration of cleaning procedures, (2) modifications of present methods of removing membrane foulants by the use of various cleaning agents not now employed, (3) by substitution for the currently used chemicals and components employed in the dyeing process to avoid or reduce membrane fouling.

\section{ECONOMICS}

An aspect of the practicality being demonstrated is the economics. HF is a technology that affects pollution control by recycle and recovery. The capital, including installation, costs, and the operating costs, including membrane maintenance, have been determined. The savings from recycle of energy, chemicals and water and the reduction of waste treatment or disposal costs are dependent on the specific conditions at any site. The potential savings at La France, when chemical recovery is implemented and membrane washing procedures are better developed to maintain $100 \%$ unit capac1ry, result in a payout time of 3.5 years. In other selected industrial situations where hot (to $100^{\circ} \mathrm{C}$ ) waste streams contain chemicals up to $\$ 0.025 / 1$ iters ( $\$ 100 / 1000$ gallons) and water and waste treatment costs up to $\$ 0.001 /$ liters ( $\$ 4 / 1000$ gallons), the payout time can be as short as 1.3 years after taxes. The payout time for $\mathrm{HF}$ can vary from a year to several years, but when properly applied there will be a positive, and attractive, rate of return on the investment in $\mathrm{HF}$. $\mathrm{BF}$ is best applied where there are simultaneous benefits for water, energy and chemical recovery and/or where significant waste treatment costs can be abated by reuse and/or volume reduction of the pollutant for ultimate disposal. 
FOREWORD

ABSTRACT

CIMMARY

GURES

TABLES

METRIC CONVERSIONS

ACRNOWLEDGEMENTS

$\frac{\text { Section }}{1}$

INTRODUCTION

HYPERF ILTRATION

ENERGY RELATED PROBLEMS

PURPOSE AND SCOPE

METHOD OF STUDY

OVERALL RESULTS

2 CONCLUSIONS

3 RECOMMENDATIONS

4 TEXTILE PROCESS DESCRIPTION

DYE RANGE

PRODUCTION HISTORY BASELINE

EFFLUENT CHARACTERISTICS

5 RECOVERY SYSTEM

DESIGN

OPERATION

INSTALLATION

6

H. F. UNIT PERFORMANCE

PERMEATE QUALITY (MEMBRANE REJECTION)

PERMEATE QUALITY (MEMBRANE FLUX)

LONG TERM EFFECTS

H. F. UNIT AVAILABILITY

7

RECOVERY PROCESS

PERMEATE REUSE

CONCENTRATE REUSE

8 POLLUTION ABATEMENT

DISPOSAL TECHNIQUE DESCRIPTION

9 RECOVERY SYSTEM COST ANALYSIS

COST DATA FOR LA FRANCE

FACTORS WHICH INFLUENCE COSTS AND SAVINGS

MEASURES OF MERIT

REFERENCES

APPENDICES

A
B
C
D
E
F 


\section{FIGURES}

Schematic of Dye Range and Recovery System

Dye Range Consumption and Production Characteristics

Dye Range Production Characteristics for Lot Size and Dye Class

Schematic of Dye Range and Recovery System with Design Flow

Rates

5 Estimated Drug Room and Make Up Flow Rate

6 Single Pass Membrane Flow Configuration

7 (a) Differential Membrane Element

7 (b) Single Pass Membrane System Arrangement

8 Single Pass System Pressure Profile

9 Relative Permeability versus Time for the Upstream Seven Modules

10 Relative Permeability versus Time for the Downstream Three Modules

11 Flux versus Total Solids Concentration - Concentrate Disposal

Membrane Performance

12 Flux versus Pressure - Concentrate Disposal Membrane Performance

13 Energy Savings per Volume Processed Versus Process Temperature for High Temperature Recovery of Hot Water.

14 Payout Time (POT), Internal Rate of Return (IRR), and Return on

15 Original Investment (ROI) versus Savings for the Demonstration

15 Effect of Flux on Measures of Merit for Demonstration Recovery System 


\section{TABLES}

1 Energy \& Material Recovery Potential for the U. S. Textile Industry

2 Project Milestones

Chemical Characteristics of the Dye Range Effluent

Selected Membrane Performance Parameters Throughout the Course of the Demonstration

5 Relative Membrane Permeability on Water After Washing

6 Recovery System Availability

7 Total Solids Analysis for Concentrate Disposal Testing

8 Results of EP Toxicity Testing on Hyperfiltration/Evaporation Sludge and Incinerated Ash

9 Capital Cost Data for Hyperfiltration Demonstration

10 Capital Cost Data for Subsequent Hyperfiltration Applications Based on this Demonstration

Annual Operating Expense Data for Demonstration

$\mathrm{HF} /$ Dye Range - Energy and Water Use Summary

Current Annual Savings Data for Demonstration

Sumary of Factors Affecting Costs \& Savings for Textiles 
ENGLISE-METRIC CONVERSION TABIE*

\begin{tabular}{|c|c|c|}
\hline To Convert From & To & Multiply by \\
\hline Inch & Meter & $2.54 \times 10^{-2}$ \\
\hline - Feet & Meter & $3.05 \times 10^{-1}$ \\
\hline Square inch & Square meter & $6.45 \times 10^{-4}$ \\
\hline Square feet & Square meter & $9.29 \times 10^{-2}$ \\
\hline Cubic feet & Cubic meter & $2.83 \times 10^{-2}$ \\
\hline -Gal1on & Cubic meter & $3.79 \times 10^{-3}$ \\
\hline Pound & R1logram & $4.54 \times 10^{-1}$ \\
\hline Pound per sq. Inch (psi) & Atmosphere & $6.80 \times 10^{-2}$ \\
\hline Eorsepower (Hp) & Wate & $7.46 \times 102$ \\
\hline Gallon per day & Cuble meter per day & $3.79 \times 10^{-3}$ \\
\hline Gallon per minute (GPM) & Cubic meter per day & 5.45 \\
\hline Gallon per sq. Et-day (GFD). & Cublc meter per sq. meter-day & $4.10 \times 10^{-2}$ \\
\hline Gallon per miaute per sq. Et. & Cuble meter per sq. meter-day & $5.87 \times 101$ \\
\hline
\end{tabular}

The units most familiar to the projected readership of this report have been maintained. 


\section{ACKNOWLEDGEMENTS}

This study was conducted by a team and major contributions were made by a number of people. The cooperation and assistance of the La France staff members is particularly acknowledged: Mike Drummond, Perry Lockridge, Charles Smith, Al Whitney and many machine operators and laboratory technicians. Dr. Jim Bostic, Jr., Mr. Ted Meyer and Mr. Ernie Freeman of Riegel Corporate staff provided valuable advice.

This demonstration is an interagency program and thus benefited from the guidance of $\mathrm{Dr}$. Max Samfield and Robert Hendriks, U. S. Environmental Protection Agency, as Principal Project Officers; John Rossmeissl and William Sonnett, Department of Energy, and Frank Coley, Department of the Interior, as Project Officers; and Mr. Robert Mournighan, U. S. Environmental Protection Agency, as Technical Advisor. Dr. J. S. Johnson, Jr., of the Oak Ridge National Laboratory has served as membrane technology consultant on this and all the previous related research and development projects.

CARRE, Inc. provided overall program management and engineering design of the recovery system. The contributions of staff members at CARRE, Inc. are acknowledged. Staff members making major contributions are Drs. J. $L$. Gaddis and H. G. Spencer; Donald K. Todd and Daniel A. Jernigan, engineers; and Roger Hunt, Don King and Cindy Cochran, technicians.

Dr. J. J. Porter and Mr. Grant Goodman of Texidyne, Inc. made significant contributions in providing chemical analyses and textile process consultation. Dr. E. Harrison served as a consultant on control and instrumentation.

The detailed design and bid specifications were provided by the J. E. Sirrine Company. The membrane equipment vendors made significant contributions in technical comments 
The technical feasibility of using hyperfiltration to renovate textile wastewater for direct recycle has been shown, at pilot scale, in a series of research projects conducted as part of a cooperative program between the textile industry and the U. S. Environmental Protection Agency which began in 1972 .

The current project to demonstrate at full scale, the use of hyperfiltration with a production dye range establishes the practicality of hyperfiltration. This project is funded by a cooperative agreement between the Departments of Energy, and Interior, the Environmental Protection Agency and La France Industries, a Divison of Riegel Textile Corporation. This report summarizes the results of the demonstration program.

The wide scale application of hot process effluent recycle/reuse has a large potential impact on pollution abatement. The cost of achieving this pollution abatement with hyperfiltration will be offset by a combination of savings from the simultaneous recovery of energy, water, and chemicals. If subsequent waste treatment is required of all or a portion of the chemicals, the cost of this treatment will probably be less because of the volume reduction achieved by hyperfiltration.

\section{HYPERF ILTRATION}

Hyperfiltration is a membrane separation process operating on the principle of selective diffusion through a semi-permeable membrane, achieved by pressure differential. Since the separation is achieved without a change of phase, membranes are inherently energy efficient. The optimized Single Pass arrangement (U. S. Patent No. 4200533 of CARRE, Inc.) which requires no recirculation of any concentrated material, utilizes approximately four BTU's per pound of water passing through the membrane. The energy used is generally electrical energy to operate the pumping system. Converted to an equivalent therinal basis this would be approximately 12 BTI's per pound of water separated. Change of phase technologies such as freezing and evaporation, require four to forty times as much energy per pound of water separated.

Initial interest in membrane separation was largely directed to reverse osmosis of sea and brackish water. Attempts to utilize the technology thus developed in industrial situations encountered limitations dictated by 
temperature and composition of the typical individual waste streams. The innovation of high temperature zirconium oxide/polyacrylic acid membranes (U. S. Department of Energy Patent Nos. 3,431,201, 3,449,245, and 3,503,789 zensed to CARRE, Inc.) dynamically formed on sintered stainless steel bes, which operate under a wide range of corrosive conditions at high pressure and temperature, and are able to withstand high suspended and dissolved solids as well as bacteriological attack, constitutes a breakthrough in membrane separation technology that relaxes these limitations. These high temperature membranes are utilized in the hyperfiltration system being demonstrated.

\section{ENERGY RELATED PROBLEMS}

Two trillion gallons of hot water are discharged by industry each year. Thus literally about $6 \%$ of all the energy consumed by industry goes down the drain. Much of this hot water is "contaminated" with chemicals and other dissolved or suspended material which not only constitute a hazard to the environment, but represent an additional "waste" of materials which requires substantial energy to produce or replace. Additionally, much energy is expended by industry to remove water from the industrial waste stream to achieve desired levels of chemical concentration to permit reuse, or to reduce the volume of materials to be stored, processed, or transported.

Many, if not most, industrial situations in which the manufacturing process involves industrial waste water have similar requirements:

1. A contaminate level that requires reduction to permit hot water recycle; and/or

2. A water content of the dissolved chemicals or suspended solids that requires reduction to permit the simultaneous recycle or recovery of both the water and the solids.

Often, the simple separation between the water and solids in the typical industrial waste stream will permit the simultaneous recycle or recovery of both the water and the solids.

Despice this gimilarity, each industrial wate stream contains unique features which must be considered not only as to the type of separation but the economic soundness of a program of recycle and recovery. The uniqueness may be in the type of corrosiveness (i.e., acid, base, oxidant, etc.); the specific separation required; the type of foulants which may lead to reduction of the performance of the separation equipment; and other characteristics of the particular industrial waste stream.

The ultimate impact on industry could approsch $5 \%$ of present energy 
THIS PAGE

\section{WAS INTENTIONALLY LEFT BLANK}


TABLE 1. ENERGY AND MATERIAL RECOVERY POTENTIAL FOR THE U. S. TEXTILE INDUSTRY ${ }^{1}$

\begin{tabular}{|c|c|c|c|c|c|}
\hline & $\begin{array}{c}\text { Water } \\
\text { Discharge } \\
\left(10^{3} \mathrm{~m}^{\Xi} / \mathrm{d}\right) \\
\end{array}$ & $\begin{array}{c}\text { Dyes } \\
\left(10^{3} \mathrm{~kg} / \mathrm{d}\right)\end{array}$ & $\begin{array}{l}\text { Auxiliary } \\
\text { Chemicals } \\
\left(10^{3} \mathrm{~kg} / \mathrm{d}\right)\end{array}$ & $\begin{array}{c}\text { Salt } \\
\left(10^{3} \mathrm{~kg} / \mathrm{d}\right)\end{array}$ & $\begin{array}{c}\text { Process Thermal } \\
\text { Energy } \\
\left(10^{9} \text { BTU/d) }\right.\end{array}$ \\
\hline $\begin{array}{l}1978 \text { Study Total } \\
\text { Industry Total } \\
\text { Recycle Potential }\end{array}$ & $\begin{array}{c}120 \\
2700^{c} \\
2400\end{array}$ & $\begin{array}{r}27 \\
1000 \\
60\end{array}$ & $\begin{array}{l}13 b \\
270 \\
222\end{array}$ & $\begin{array}{r}12 \\
264 \\
220\end{array}$ & $\begin{array}{r}38 \\
784 \\
352\end{array}$ \\
\hline $\begin{array}{l}\text { Estimated Annual Savings } \\
\left(\$ \times 10^{6} / \mathrm{yr}\right)\end{array}$ & 120 & 158 & 36 & 2.6 & 616 \\
\hline
\end{tabular}

EPA Report No. EPA-600/2-78-047

Exclusive of $80,000 \mathrm{~kg}$. of $\mathrm{NaOH}$ used dally at these plants.

c 1972 census of manufacturers, assuming 250 days/year.

Unit costs: water e $\$ 0.2 \mathrm{~m}^{3}$; dye e $\$ 213 / \mathrm{kg}$; auxiliary chemicals a $\$ 0.66 / \mathrm{kg}$; salt e $\$ 50 / 1,000 \mathrm{~kg} . ; \mathrm{process}$ stream $\$ 7 / 10^{6}$ BTU. 
equipment and installation. They also received and reviewed the quotations.

The method of study is illustrated in the List of Milestones, Table 2 . sitially the period of the project was September 23, 1977 to April 22, 1982. (Currently the project is being continued through September, 1983). There was no project activity from September, 1978 through March, 1979 while the decision was being made about continuation following Phase $I$, the design phase.

OVERALL RESULTS

A Phase I design report was published, EPA $600 / 2-80-055^{2}$. The two major results of the study and design activities of Phase I were:

1. The selection of the continuous dye range instead of the dye becks for the full scale demonstration.

2. The determination that hyperfiltration, based on the quotations for installed costs, had the potential to achieve a practical approach to zero discharge with a positive rate of return on the investment when energy and chemical conservation were fully realized.

The continuous dye range was selected because it is the more modern dyeing equipment technology and is representative of the trend in the industry due to the lower production costs associated with this method. At the demonstration site, the dye range has largely replaced the becks as the standard production equipment.

During Phase II and Phase III, the Single Pass hyperfiltration unit was installed beginning in January, 1981, and is producing water for recycle. Over a willion yards of velour fabrics have been washed with recycled water. The hyperfiltration unit is being operated by production personnel. The procedures for reuse of the dyes and auxiliary chemicals have been developed on a laboratory basis. Initial tests with production lots of 4,000 yards of velour have been achieved in the first quarter of 1982. This project initially scheduled to be concluded in April, 1982, is being extended through September, 1983 to better establish the reuse of chemicals in production. During this extended period the performance of the membrane system will continue to be monitored to further establish membrane lifetime and operating cost. The initial membranes installed in January, 1981 are still in operation as of March 1, 1982. The study of membrane fouling will be a major study effort during the extended period with the goal of increasing average unit capacity.

The capital costs, including installation, were $\$ 484,000$. The operating costs including membrane maintenance are $\$ 119,900 /$ year. The savings have not been fully realized because procedures for chemical reuse in production are still being developed and the capacity of the HF unit is limited by fouling to a time average of about $60 \%$ of design capacity. When the potential savings are realized, the payout time will be 3.5 years. Even at current levels of reuse and $H F$ performance there is a net savings of over $\$ 40,000$ per year. 
TABLE 2. PROJECT MILESTONES

\begin{tabular}{ll}
\hline 1. Detalled Work Plan Completed & 11 November 1977 \\
2. Process Selected & 31 May 1978 \\
3. Recovery System Design Completed & 31 July 1978 \\
4. Equipment \& Installation Bids Received & 31 August 1978 \\
5. Project Continuation Authorized & 6 Apri1 1979 \\
6. Auxiliary System Installed & 30 November 1980 \\
7. Hyperfiltration Unit Installed & 1 May 1981 \\
8. Permeate Recycle on Production Basis & 12 May 1981 \\
9. Interim Final Report & 15 September 1981
\end{tabular}


CONCLUSIONS

For twelve months a production size HF unit has been integrated with a manufacturing dye range resulting in the full scale recycle of hot wash water from a dynamic membrane hyperfiltration system. The results have demonstrated satisfactory use of permeate recovery from all types of effluents from this multi-purpose range. One million meters of fabric have been produced with recycle wash water.

Full scale use of the HF concentrate to formulate solutions for dyeing has been demonstrated in selected cases. Two lots of 4,000 meters each have been dyed with HF concentrate plus dye additives. The eventual extent of such reuse of $H F$ concentrate will depend on experience and the economic incentive.

Throughout the twelve months of demonstration, the membranes have remained stable with respect to rejection. It has been demonstrated that stainless steel tube bundles may be used in reforming membranes after several months of exposure to wash water. Although permeate is always used when available, because of membrane fouling its availability is limited to about $60 \%$ of the production. Membrane cleaning and foulant removal procedures will be developed during the extended evaluation period.

No build up of solute components was observed in the permeate during a continuous recycle run of four hours, thus the expected normal continuous recycle period of eight to twenty-four hours should not be limited by component build up.

The capital and operating costs of $\mathrm{HF}$ were found to be about as projected in 1977. The payout time for the capital cost of this demonstration will be 3.5 years (after taxes) when the full potential for reuse is achieved. In situations where there are simultaneous benefits for water, energy, and chemical recovery and/or where significant waste treatment costs can be abated by reuse or by volume reduction of pollutants, HF will yield a payout time as short as 12-15 months (after taxes).

Disposal of HF concentrate was studied. The technical feasibility of incineration after further concentration and drying was shown. Thus a method of complete on-site disposal was shown. Further study is required to determine the practicality of incineration because of the cost of commercial units wich are not designed for the small capacities required. (There are no disposal problems in biological treatment created by the HF concentrate.) 
Hyperfiltration should be considered a practical technology for a wide variety of industrial applications. When applied in situations where energy, water, and material conservation can be achieved simultaneously the payout time can be as little as 12-15 months after taxes. Pollution abatement meeting the 1983 national discharge goals can be achieved practically, in that:

(1) reuse and recycle will reduce pollution discharges, and

(2) the volume reduction achieved (by factors of 10 or more) by hyperfiltration will permit cost effective disposal by evaporation, incineration and/or land disposal.

(3) The value of savings will replay the capital and maintenance costs of the HF recovery system.

The extended period of this project will permit continued investigation of foulant removal and the development of chemical reuse techniques at the demonstration site. The success of this demonstration has encouraged research and development of other applications in the textile industry and in other industrial situations.

The dynamic membrane formation techniques permit the possibility of tailoring membranes to a wide variety of industrial environments. Research and development in the area of membrane tailoring is a promising area of investigation to accelerate the wide use of this potentially cost effective technology to meet the 1983 national discharge goals by recycle/reuse and/or volume reduction of pollutants for ultimate disposal. 
The wash water, HF supply, is characterized by being highly colored and quite "hard." The hardness is the result of chemicals added in the dye formulations because both the plant water and HF permeate are relatively soft. The wide $\mathrm{pH}$ range is the result of the inclusion of the scouring and bleaching effluents along with the dye wash water. The organic content of the wash water is not large, as indicated by the TOC and COD parameters. Simple dilution of the dye pad would indicate higher values of organics. However, of course, most the dyes are exhausted into the fabric and do not appear in the wash water. This exhaustion is also indicated, qualitatively, by a comparison of the color in the pad and wash water.

\section{DYE RANGE}

The textile processes involved in this project are conducted on a continuous dye range. The range and its operation are described in this section. The production history beginning in January, 1980, forms the baseline for evaluating this demonstration project. The chemical characteristics of the range effluent, the supply to the hyperfiltration membrane, are also presented.

Most of the dyeing production is done on the continuous range. The range is also used for bleaching and scouring and consists of a dye applicator, a spiral atmospheric steamer, and a washing section shown in Figure 1 . The types of fabrics processed include cotton, acrylic, nylon, rayon, and polyester fabrics as well as their blends. The range is fully automated to control cloth speed, process temperature and water flow rate. The range processes fabric from 9 to 36 meters per minute depending on the type and the process details. The range is operated three shifts per day, five to seven days per week.

Fabric moves sequentially through the dye range components beginning with the dye pad. Process formulations are mixed in the drug room and pumped to the pad where they are applied to the fabric. No formulation is applied to fabric during the scouring operation. The applicator is a 50 meter tank in which the fabric is saturated. Excess chemicals are removed from the fabric by squeeze rollers as it leaves the pad and before entering the steamer. The temperature is maintained at $100^{\circ} \mathrm{C}$ in the steamer for all range processes. The steamer holds approximately 150 meters of fabric so range speed is $a$ function of residence time required by process details.

Fabric moves from the steamer to a series of washers where excess dyes and process chemicals are removed. The washing train consists of jet washer, dip box, and two rotojet washers. Squeeze rollers follow the dip box and each rotojet washer. The jet washers and the two rotojet washers incorporate large recirculation flow rates which pass through 100 mesh lint filters. The 


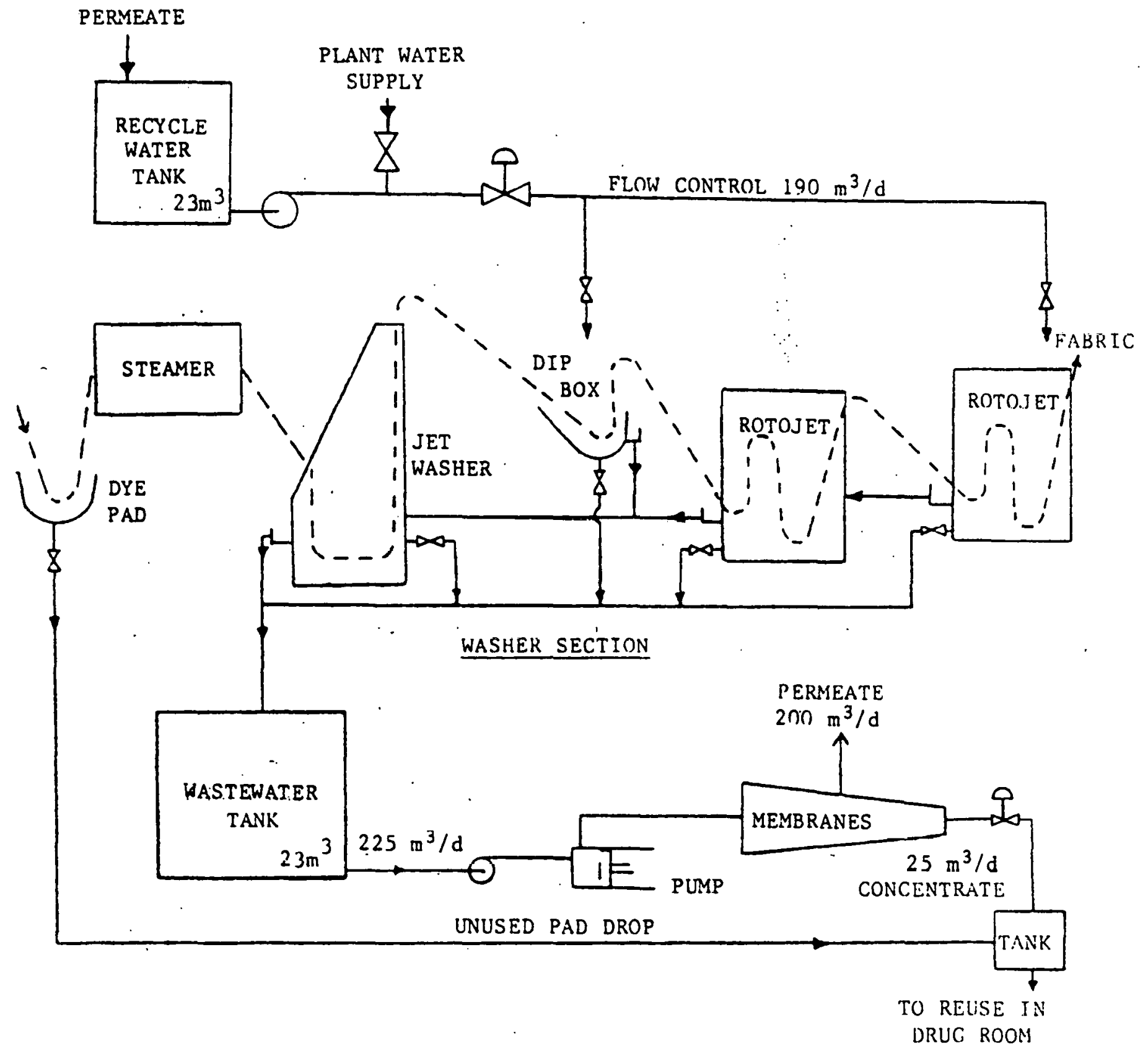

Figure 1. Schematic of Dye Range and Recovery Sygtem 
majority of range wash water enters the second rotojet which overflows to the first rotojet which in turn overflows into the jet washer. A smaller amount : water enters the dip box and overflows to the jet washer. The jet washer rerflow becomes the supply to the recovery system. Water flow to the range is automatically controlled at the operator control panel. Steam is injected into the dip box and rotojet washers to maintain the controlled process temperature.

\section{PRODUCTION HISTORY BASELINE}

Records of range production were kept beginning in 1980 before process modifications and the installation of the recovery system. These records comprise a baseline of data to determine the effects of the changes made in range operation by counterflow, reduced wash water flow and by recycle of wash water.

Figure 2 shows specific consumption of water, steam, and dyes and chemicals beginning in January, 1980. Normalized production numbers are included to show relative rates of production during each week. The baseline portion of the data extends from January 1, 1980, to April 1, 1981 (63 weeks) after which the rate of water flow delivered to the range washers was reduced from about $400 \mathrm{~m} / \mathrm{d}(75 \mathrm{gPm})$ to $200 \mathrm{~m} / \mathrm{d}(35 \mathrm{gpm})$. Energy use dropped with the reduction of water use as expected.

The baseline of dye range production characteristics which could influence recycle of concentrate and permeate is included on a monthly basis in Figure 3. The figure includes the normalized average dye lot size for each month and a breakdown of production type as a fraction of total production. Larger production lots result in larger volumes of a concentrate increasing the ease of chemical. reuse. The membrane color rejection is different for the various production types so a significant shift in production trends could influence permeate recycle.

\section{EFFLUENT CHARACTERISTICS}

Several classes of dyes are used: direct, basic, disperse, acid and reactive. The wash water effluent components vary in dye class and concentration but the types of components are common to all the wash water from the dyeing operations. The dye formulations contain dyes, a thickener (guar gum), surfactants, and in some cases, dye solvents. While about $85 \%$ of the dyes are exhausted on the fabric, the remaining dyes and most of the auxiliary components are removed by the washing process. Practical analysis of composite effluents from the dye pad applicator, the washing section and the plant tapwater, are presented in Table 3. Fabric washing studies showed that the amount of water used could be reduced by $50 \%$ or more without a 1088 in washing efficiency. Water flow to the range has been reduced to as lnw as 113 liters per minute ( $30 \mathrm{gpm}$ ) for long periods of time without any observed affect on quality of produced goods. The standard operation is now set at 138 liters per minute ( $35 \mathrm{gpm}$ ). 


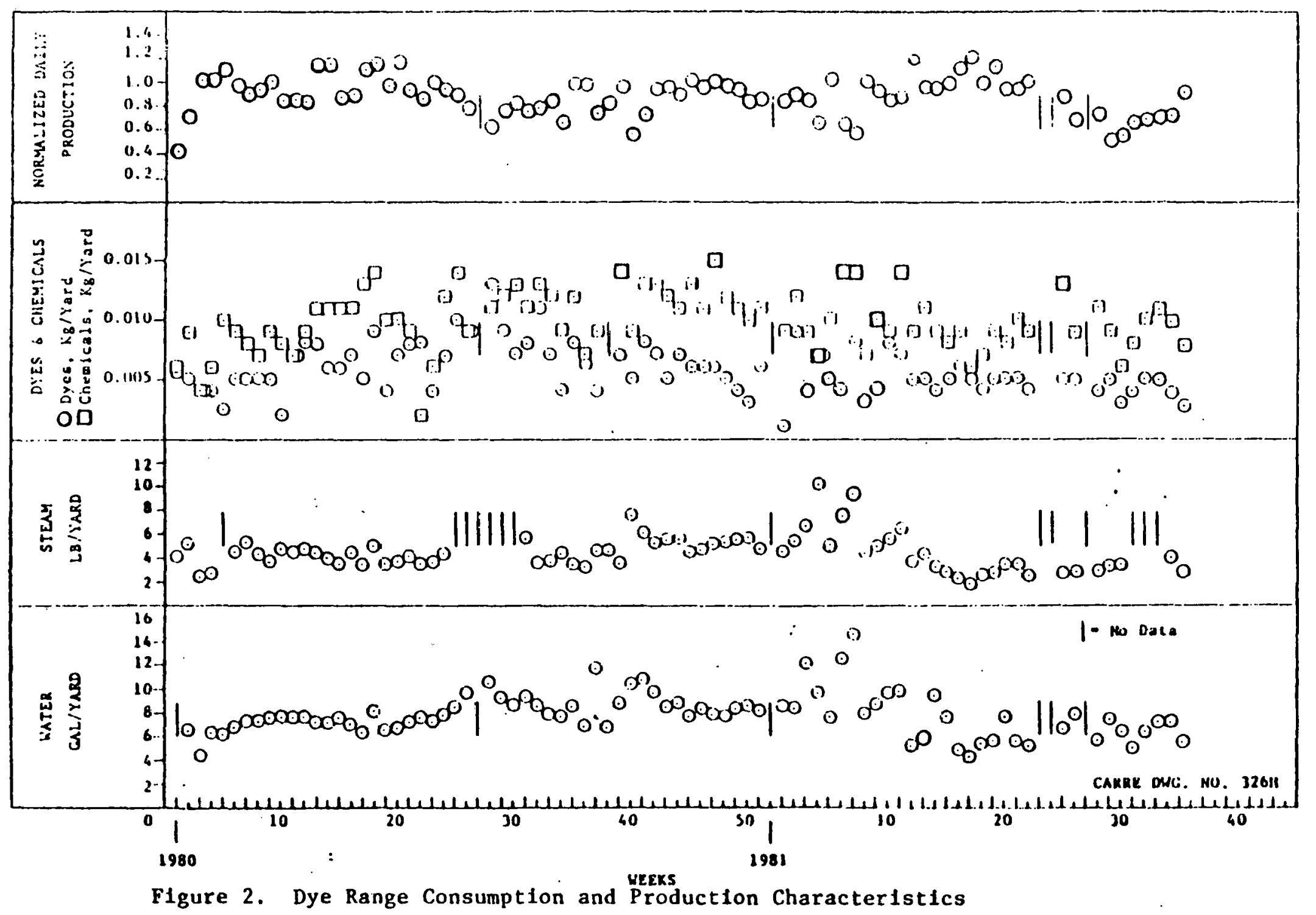



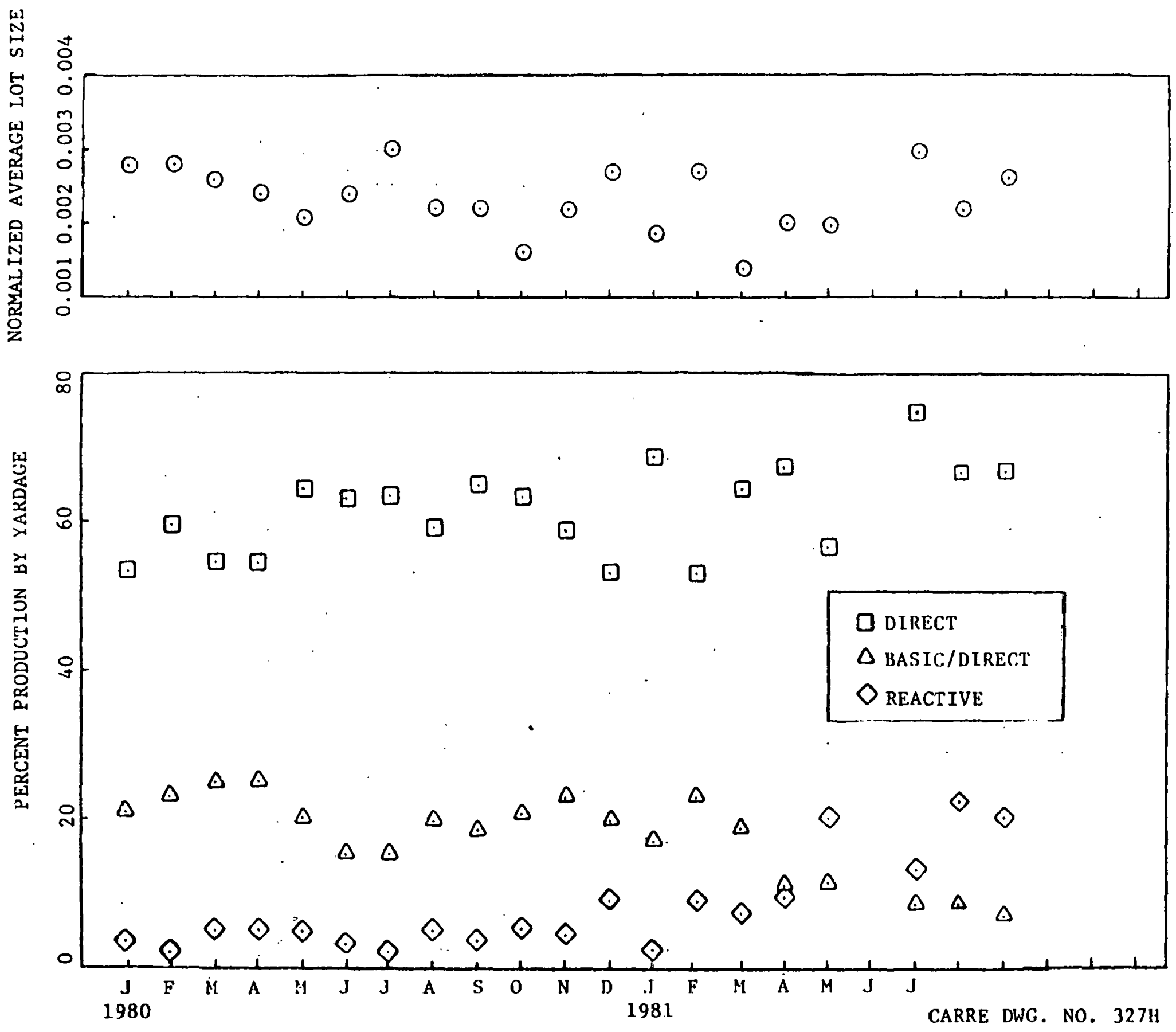

Eigure 3. Dye Range Production Characteristics for Lot Size and Dye Class 
TABLE 3. CHEMICAL CHARACTERISTICS OF THE DYE RANGE EFFLUENT

\begin{tabular}{|c|c|c|c|}
\hline \multirow[b]{2}{*}{ ASSAY } & \multicolumn{3}{|c|}{ Average concentration or flow } \\
\hline & Dye Pad & $\begin{array}{l}\text { Composite } \\
\text { Effluent }\end{array}$ & Tap Water \\
\hline Flow, $\ell / m i n$. & $12-35^{a}$ & 138 & - \\
\hline BOD, $\mathrm{mg} / \mathrm{l}$ & 5,400 & 200 & - \\
\hline$C O D, \mathbf{m g} / \ell$ & 23,900 & 1,200 & 9 \\
\hline Conductivity, $\mu S / \mathrm{cm}$ & $1580-28,000^{b}$ & $200-2,000^{b}$ & 90 \\
\hline Alkalinfty, mg/l & 4,150 & 180 & - \\
\hline Color, ADMI & 98,800 & 1,750 & - \\
\hline Hardness, mg/ $\mathrm{l}$ & $-^{c}$ & 30 & 9 \\
\hline $\mathrm{pH}$ & $3.6-10.9^{b}$ & $5.0-10.5^{b}$ & 7.05 \\
\hline Phenols, mg/l & 0.84 & $-d$ & - \\
\hline TOC, $\mathrm{mg} / \mathrm{l}$ & 6,250 & 325 & - \\
\hline Total Solids, mg/e & 20,900 & 1,140 & 60 \\
\hline Suspended Solids, mg/l & 1,730 & 45 & 3 \\
\hline Dissolved Solids, $\mathrm{mg} / \mathrm{l}$ & 19,200 & 1,100 & 57 \\
\hline Chromium, mg/e & 5.3 & 0.2 & 0.002 \\
\hline Copper, mg/2 & 19.2 & 0.2 & - \\
\hline Iron, $\mathrm{mg} / \mathrm{l}$ & 2.8 & 0.63 & 0.022 \\
\hline Manganese, mg/l & 0.2 & 0.1 & - \\
\hline Nickel, mg/l & 0.1 & 0.007 & - \\
\hline Zinc, mg/e & 2.7 & 0.25 & - \\
\hline Magnesium, mg/l & 10.4 & 8.5 & 1.00 \\
\hline Calcium, mg/l & 7.4 & 3.5 & 2.36 \\
\hline
\end{tabular}

a Dye pad flow depends on cloth pickup. Pad drops bypass recovery system to join $\mathrm{HF}$ concentrate.

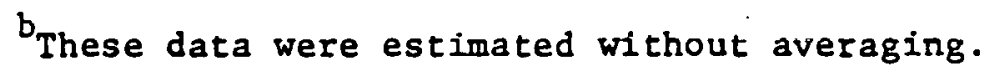

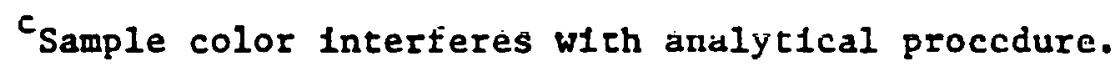

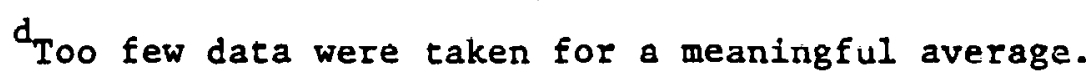




\section{SECTION 5}

\section{RECOVERY SYSTEM}

The recovery system is designed to collect all water from the dye range and supply the fluid to the hyperfiltration (HF) system. The permeate from the HF system is returned to the range as hot wash water and the concentrate is collected for reuse or disposal. The design provides operation of the range independent of operation of the HF system. Automatic controls allow for continuous operation. Additional instrumentation is installed to record operation parameters of economic importance.

In the discussion which follows, only a portion of the detailed design specifications are mentioned. (Detailed specifications used as a basis for the quotation are available from the EPA Project Officer.) Emphasis is given to the aspects of design which affect the system function rather than materials and other design aspects.

\section{DES IGN}

The design wash water flow rate, as shown in Figure 4, was 174 liters per minute $(46 \mathrm{gpm})$. The assumed fabric speed was 18 meters per minute. At 18 meters per minute speed, 159 liters per minute of water is supplied to the washers and 18 liters per minute of dye formulation is applied to the fabric. The moisture added in the steamer less the amount of drag out from the last washer and the vapor loss from the hot fabric comprise the total mass balance of water.

The average lot size was taken as 10 pieces of fabric (one piece $=50$ meters). Each lot is separated by approximately 20 minutes from the next lot. During this 20 minutes time the wash water flow is continued. (In the original design it was assumed that the washers would be drained.) The total volume drained during this average cycle results in an average flow rate of 174 liters per minute.

The tanks were sized to accommodate surges representing maximum deviations in water use and also provide for about two hours of membrane system down time. The maximum deviation envisioned was two consecutive shifts with consecutive 80 piece lots. The concentrate tank was sized to accept one loading of an 80 piece dye run, 3000 liters ( 800 gallons).

The range was modified for counter-flow operation with overflow to drain from the jet washer. The flow scheme is also shown in Figure 4. The drains and overflows are collected in a sump and pumped to the recovery system feed accumulacor tank. The drain oystem is designed to accept short term surges of up to 1,514 liters per minute (400 $\mathrm{gpm}$ ) during system draining.

of the total flow supplied to the range, a substantial fraction is used to remove lint by reverse spray of three rotating filters. Approximately 23 


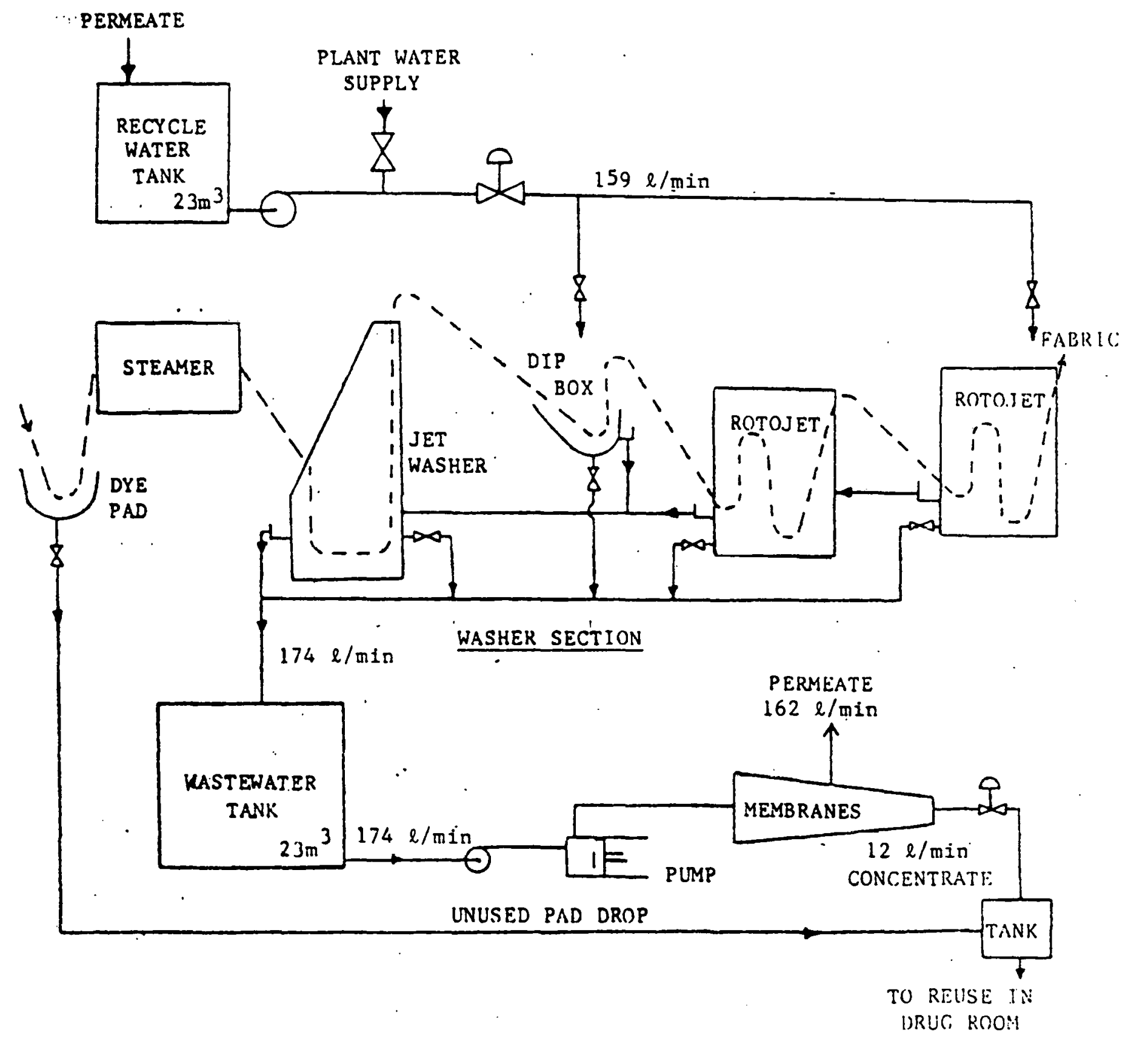

Flgure 4.. Schemat1c of Dye Range and Recovery System with Design Flow Rates. 
liters per minute ( $6 \mathrm{gpm}$ ) is used at each filter with one third escaping from the system along with the separated lint cake. Rather than using permeate for this backwash function, water is diverted from the washer circulation imps. Lint baskets of screen wire are provided to catch the separated lint trom the filters. The baskets are fitted with a fluid collection pan. The fluid draining from the lint is routed to the sump.

A pump is provided to transfer the dye pad formulation left in the applicator pad and the 75 meter line supplying the pad including washdown water to the hyperfiltration concentrate tank.

These range modifications result in a nearly complete capture of all fluids emanating from the range. Spillage still occurs with foam overflow. Adjustments to the internal circulating flows of the washers have resulted in a reduction in the amount of foam spillage.

The recovery system was designed to provide a balance in the wash water system. The flow requirements outlined above are based on assumed demands. The variations are accommodated by control of the flow to range, the HF concentrate flow control and automatic provisions for use of plant water as required. For continuous $\mathrm{HF}$ system operation the design concentrate flow was 11.4 liters per minute $(3 \mathrm{gpm})$. The flow rate to the dye applicator was estimated to be 17 liters per minute $(4.5 \mathrm{gpm})$, but varies substantially depending on the fabric type being processed. This relation, as calculated for one fabric speed and water pick-up percentage, is depicted in Figure 5. As indicated the design situation required water to be added even during short runs. This provision was designed to provide for water in the addition of chemicals to a reuse dye solution.

\section{OPERATION}

Conceptually, the cycle of operation begins with washers empty and no flow. The operator commands "high flow" and the flow valve opens completely. The rinse system pump is energized to provide permeate to fill the washers. If the permeate tank is empty, plant water automatically enters the system. When the washers are full, the range operator stops the flow by the command "interrupt." The operator signals for dye solution, sets the temperature controls (independent system) and fabric speed (also an independent system). The fabric leading edge exits the steamer several minutes after operation starts. The operator commands "controlled flow" which admits flow from the recycle water tank or the plant water supply. The counterflow overflow enters the drain system and is pumped to the HF feed accumulator tank (unless a decision has been made not to process the particular wash water in which case the water overflows the sump and enters the plant waste system.)

The HF system starts automatically when the fluid level in the accumulator tank reaches a set point. The wastewater is pumped through a regenerative heat exchanger and a steam heater where it is heated to the design temperature at $85^{\circ} \mathrm{C}$ before it enters the positive displacement pump. 


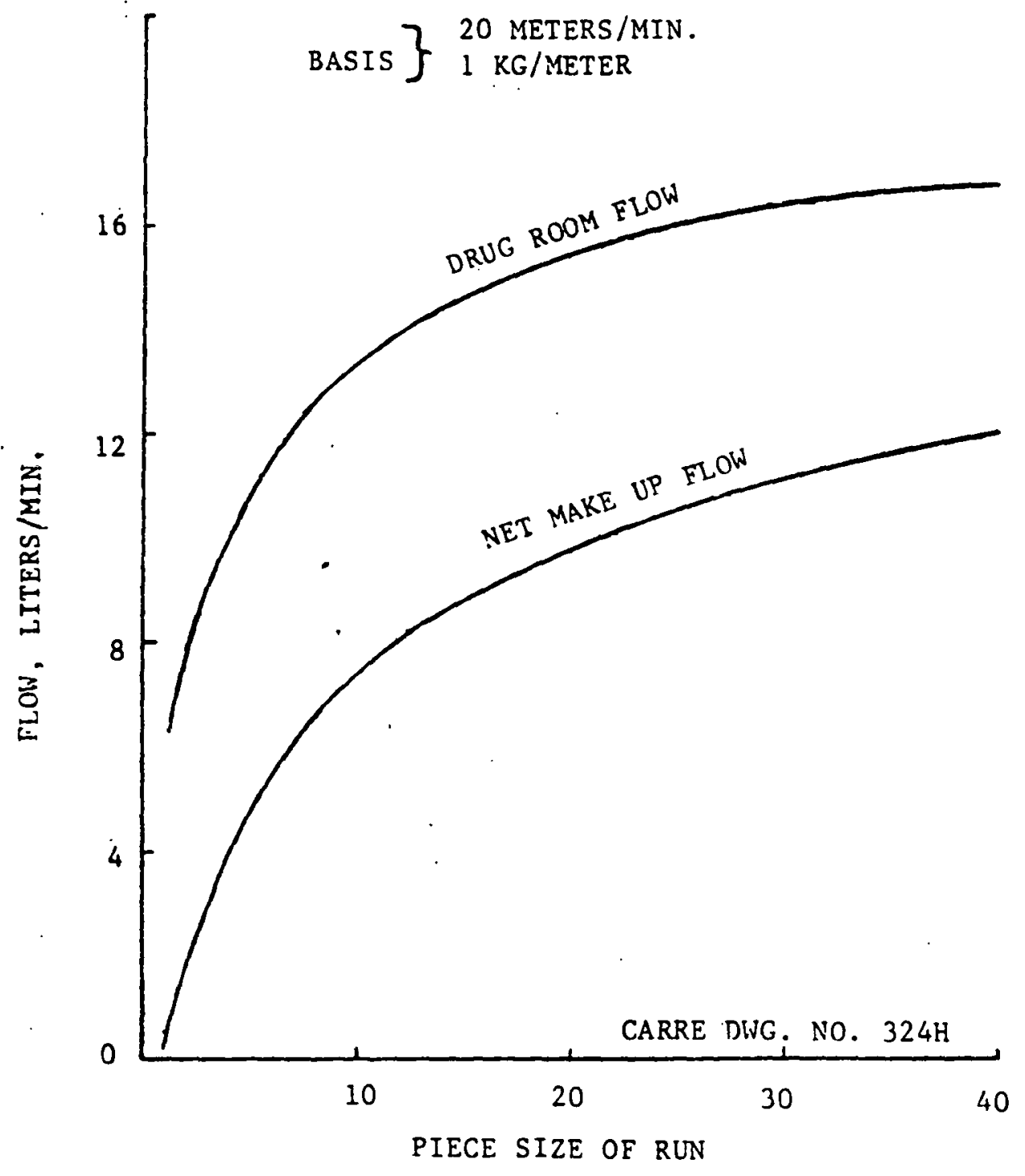

Figure 5. Estimated Drug Room and Make Up Flowrates 
When the fabric trailing edge passes the washers, the operator may elect to drain the wash boxes or allow wash water to continue to flow depending on e next color to be dyed.

\section{Controls and Meters}

Controls are provided for operating temperature of the $\mathrm{HF}$ system and flow of wash water to the range. The system automatically switches to plant water when the level in the rinse tank drops to a set point. An array of flow meters, liquid level indicators, temperature elements, steam meters, electric power meters and on time indicators were selected to allow evaluation and documentation of the recovery system performance. A more complete description and a list of controls and instruments may be found in Appendix A.

\section{HF Unit Configuration}

The $\mathrm{HF}$ unit is a Single Pass system consisting of zirconium oxide-polyacrylic (ZOPA) membranes dynamically formed on the interior of 70 segments of sintered stainless sţeel support tubes, arranged in ten modules. The total membrane area is $139 \mathrm{~m}^{3}\left(1,500 \mathrm{ft}^{2}\right)$.

The positive displacement pump pressurizes a constant flow rate into the membranes. The concentrate flow rate from the $\mathrm{HF}$ unit is controlled so the inlet pressure varies to a set upper limit at wich an automatic bypass valve opens and returns feed to the pump suction reducing the feed flow to the HF unit. A light indicates the reason for any cessation of operation and warns of operation with the bypass open.

The high pressure flow from the positive displacement pump enters a manifold which distributes the flow into an initial section comprised of seven parallel paths of $1.6 \mathrm{~cm}$ diameter tubes. The seven streams from this section are collected in a manifold and divided into four parallel paths in the second section of $1.6 \mathrm{~cm}$ tubes. Similarly the third section has three parallel paths; the fourth section, two; and the last section has only one. Each path has several tube segments connected in series. The flow path lengths are indicated in Figure 6. The firgt three sections are composed of $1.6 \mathrm{~cm}$ diameter tubes while the last two sections are $1.3 \mathrm{~cm}$ diameter tubes. The tapered arrangement of the segments is depicted in Figure 6. This arrangement was designed to yield a low velocity, low pressure drop system through the $1.6 \mathrm{~cm}$ diameter tubing. At the point where concentration becomes high enough to produce a significant effect, $1.3 \mathrm{~cm}$ diameter tubing has been used to increase the fluid velocity and minimize the concentration effect. The velocity range in the $1.6 \mathrm{~cm}$ diameter tubing was designed to be $1.5-2$ $\mathrm{m} / \mathrm{sec}$ and in the $1.3 \mathrm{~cm}$ tubing was $2-3 \mathrm{~m} / \mathrm{sec}$.

\section{INSTALLATION}

The recovery system installation began during the July, 1979, plant shutdown concurrent with the replacement of three existing washers with two 

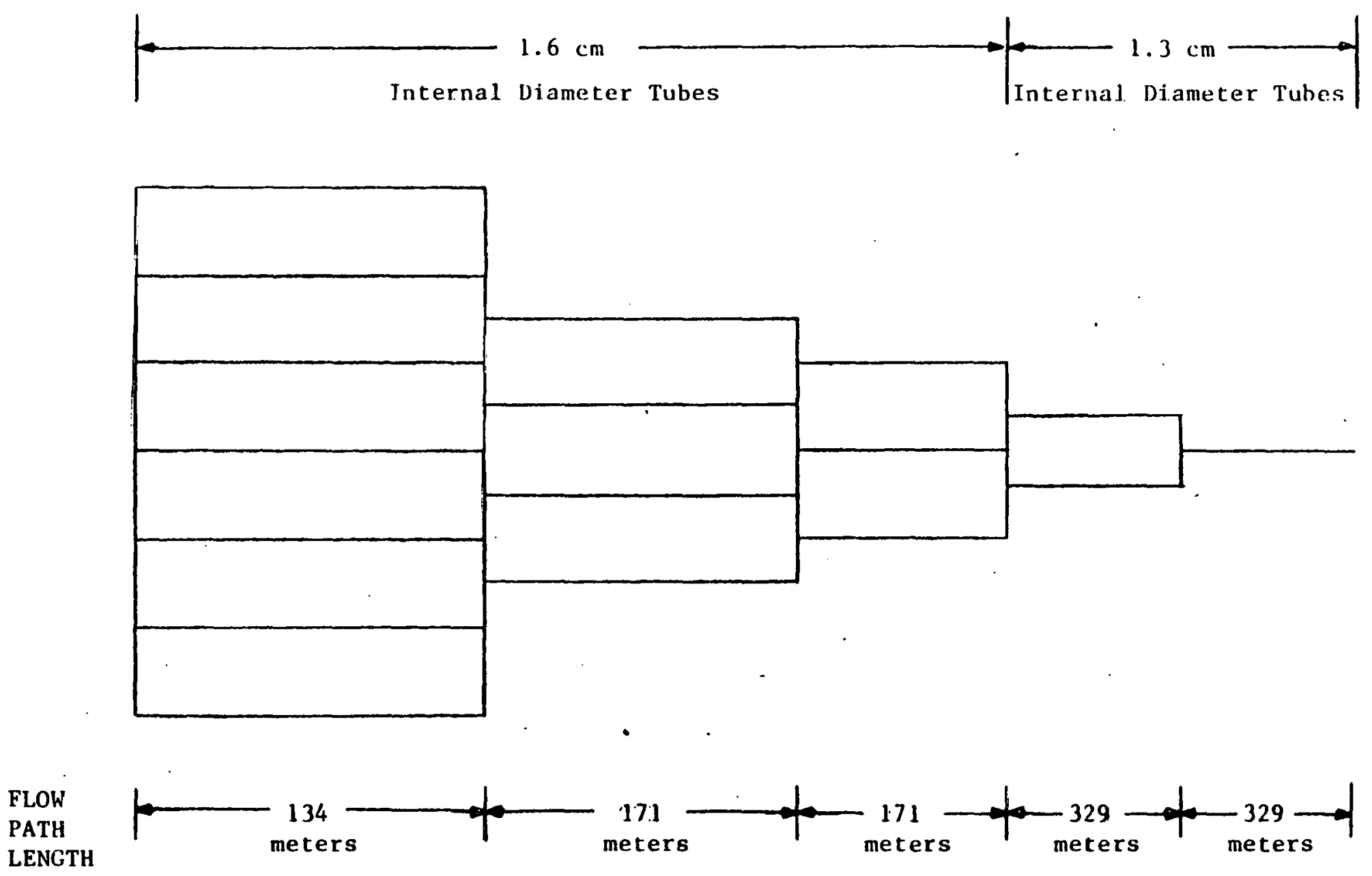

CARRE DWG. NO. $350 \mathrm{H}$

Figure 6. Single Pass Membrane Flow Configuration. 
rotojet washers (which utilize circulating flows screened by lint filters). Recovery system work included piping to incorporate counterflow water use on le range and piping to connect washer and lint filter drains to the recovery istem. A design modification was made in the recovery system at this time to incorporate a surge tank to collect the wash water from the range and to pump it to the recovery system. This surge tank replaced a diverter valve on the jet washer circulating stream. A mechanical totalizing water meter was installed at this time to measure total water used on the range.

Work continued in December, 1979, including piping on the range and foundation work for the recovery system building. Foundation problems were discovered resulting in a project delay while civil engineering studies were made and alternate locations proposed. It was decided to locate the recovery system inside the plant near the range. Preparation of the new site included cutting floor drains, installing guard rails, and fabricating pump and tank concrete pads. The $23 \mathrm{~m}^{3}(6,000$ gallon) feed and rinse make-up tanks had to be cut and field fabricated because the new location had limited access doors. A $0.75 \mathrm{~m}^{3}$ (200 gallon) stainless steel wash tank was added to facilitate membrane cleaning. Equipment installation and associated piping and electrical work continued through November, 1980. At this time membranes had not been installed, however, the recovery system controls affecting range operation, particularly the flow rate to the washers, were operational. 
Membrane Washing: Mem rnes are subject to foulin due to both dissolved and undissolved -aponents in the membrane system reed stream. In many cases particular feed constituents can be identified as foulants and can be washed from the membrane surfaces at time intervals such that the time averaged membrane performance is increased. Membrane washing during this - - oject has been complicated by the large number of industrial chemicals used

the dye range processes, particularly when new chemicals are introduced with no knowledge of their potential as foulants. The following paragraphs describe washing conducted through February, 1982. Membrane washing studies will continue as the project continues.

Water washing, especially at high temperatures (up to $100^{\circ} \mathrm{C}$ ) and at high velocity over the membrane surface, can be effective and has been used in this project. High temperatures increase solubility and diffusion rates of most substances and high flow rates cause increased shear stress at the membrane surface. While the recovery system membranes were being installed over a ten-week period, water was run at frequent intervals when range effluent from direct dye lot runs was not available (range effluents from other dye types were introduced later). Soon after the final membrane segment was installed a steam coil was added to the wash tank and hot water (up to $95^{\circ} \mathrm{C}$ ) could be used on the membranes. To compare the results of washing, membrane performance data were recorded while operating on water and used to calculate a system average membrane permeability. A list of membrane system permeabilities on water following various washes are listed for several times during the project in Table 5. Before April 24, 1981, the system operating temperature was limited to $60^{\circ} \mathrm{C}$. The membrane permeability increase between April 24 and May 11 could have resulted from increased washing temperatures.

Between May and October, 1981, the recovery system operating time increased to 3 shifts per day on all range processes except bleach. An intensive effort to wash the membranes was made in October, 1981, a sumary of which is listed in Table 5. Water washing over a weekend (approximately 30 hours) resulted in lower membrane permeability than previously obtained after water washing (October 12, 1981, versus May 11, 1981). Waste was then run on the system for 8 hours followed by an overnight and water wash (approximately 16.5 hours) resulting in membrane permeability on October 13, 1981, of nearly half that obtained in May, 1981. Washing with a water and acetic acid solution at $a \mathrm{pH}$ of 4.0 was conducted to remove hardness components. Analysis of the cleaning solution after washing indicated that nearly a kilogram of hardness as $\mathrm{CaCO}_{3}$ was removed from the membrane surfaces and the membrane permeability was increased to within $10 \%$ of the previous best system permeability in a fraction of the washing time required to wash with water alone, Table 5. Results of a second $\mathrm{pH} 4$ wash after operating with waste resulted in the same membrane permeability as after the first $\mathrm{pH} 4$ wash.

The washing sequence continued with another $\mathrm{pH} 4$ wash followed by an enzyme wash aimed at removing organic foulants such as gums. The combination 
TABLE 5. MEMBRANE PERMEABILITY ON WATER AFTER WASHING

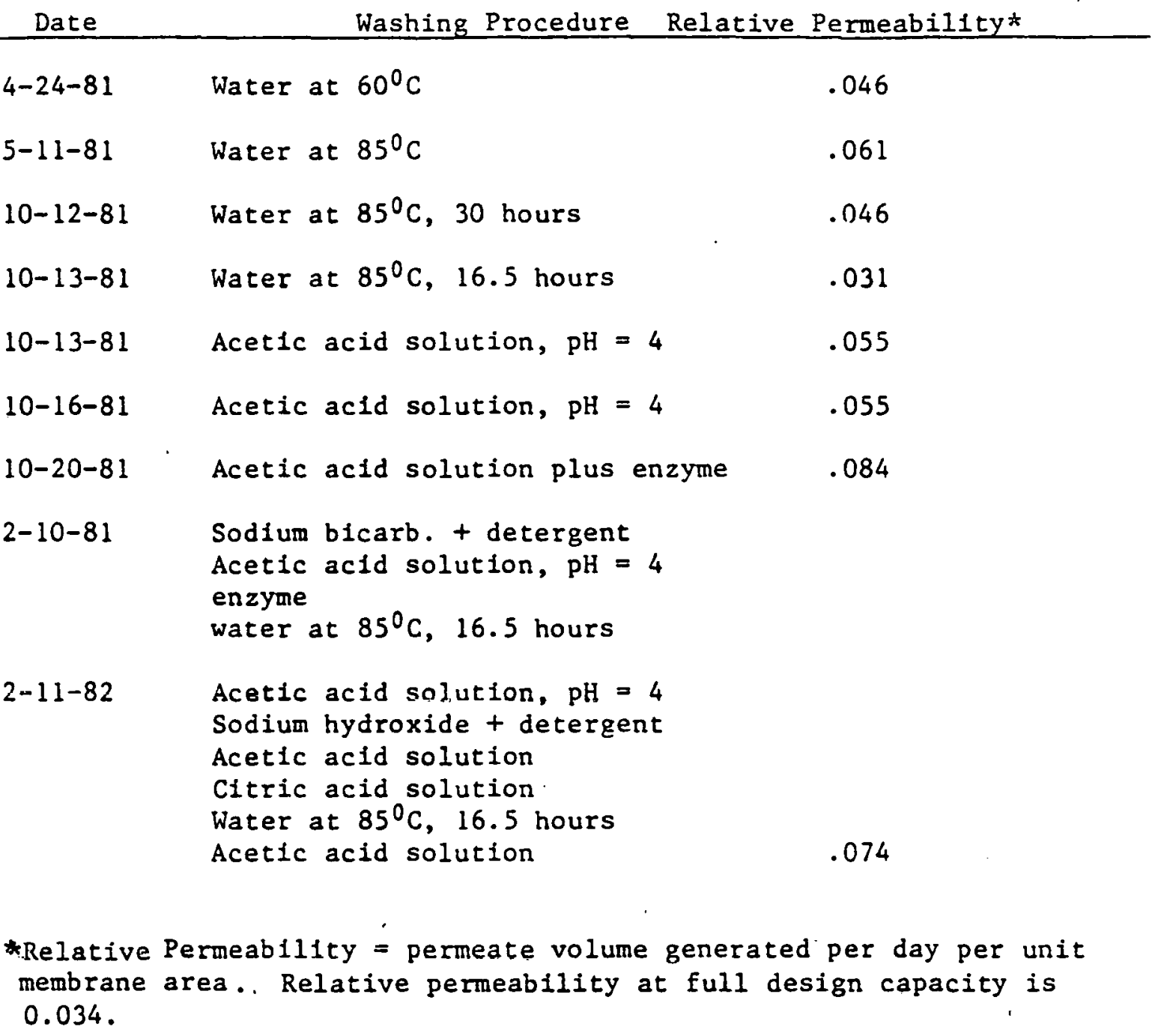


of washes resulted in the highest permeability thus far on October 20,1981 , $150 \%$ of design capacity.

In February, 1982, the membranes had been exposed to more waste without washing than at any previous time. Also, an oily substance was found in the wash tank. The oily substance was suspected to be the residual from antifoam chemicals used on the range. A sodium bicarbonate $(\mathrm{pH}=9$ ) and anionic detergent solution was used to wash as recommended by the antifoam supplier. A series of washes over a 3-day period including water, solutions of acetic acid, citric acid, sodium bicarbonate and detergent, and sodium hydroxide and detergent resulted in a membrane permeability of within $12 \%$ of the maximum permeability obtained in October. No one washing procedure caused a substantial flux increase which could indicate none were particularly effective in removing the foulant. However, if the foulants are layered on the membrane surface and the various washing procedures remove particular foulants, the sequential washing may be necessary. For example, the oil coating would prevent a $\mathrm{pH}=4$ wash or an enzyme from being effective on hardness scale or a gum layer.

Recovery system membrane washing procedures appear to restore membrane permeability even after prolonged operation with effluents from the many range processes and variations within given processes. The time required to wash may depend on the amount of effluent processed and/or the type of foulants in the fluid. Membrane washing in this complex and varying fluid is not fully understood at this time and studies will continue as the project continues. The study will include investigation of possible substitution of chemicals in production.

Two modules have been kept out of service for periods of time to study membrane washing. Because of the severe fouling problem discussed in this section, the development of effective washing procedures is important. Only a test section exposed to the history of the recovery system can provide credible results in the study of washing procedures.

Membrane Stability

Of the 70 membrane segments in the recovery syscem, 46 segments have remained. in continuous service since their installation, see Table 6 . The oldest now being in place for 13 months (from January 17, 1981, through February 25, 1982). Of the remaining 24,11 have been re-membraned after replacing a broken tube (each segment contains 12 or 16 tubes); four segments have been re-membraned after being used in washing studies, four are currently bypassed with (suspected) tube breaks, and 6 are being re-membraned after being used in washing studies. One of the segments currently bypassed is in Module $\$ 8$ that was re-membraned, thus this accounting totals 71 , instead of 70 .

The membranes in Module \#9 were originally thought to have "failed" because the color rejection was observed to decrease quickly without a corresponding major increase in permeate flow rate - as would be expected 
TABLE 6. RECOVERY SYSTEM AVAILABILITY

\begin{tabular}{|c|c|c|c|c|}
\hline Module & Installed & Removed from Service & $\begin{array}{c}\text { Returned to } \\
\text { Service }\end{array}$ & Comments \\
\hline 10 & $1 / 17 / 81$ & $12 / 3 / 81-7$ seginents & & Continuous Service \\
\hline 9 & $1 / 29 / 81$ & $12 / 3 / 81-7$ segments & & $\begin{array}{l}\text { Replace } 1 \text { broken tube; Reform } \\
\text { membrane. Module being used in } \\
\text { washing studies. }\end{array}$ \\
\hline 8 & $3 / 11 / 8 i$ & $\begin{array}{l}6 / 16 / 81-3 \text { segments } \\
2 / 16 / 82-1 \text { segment }\end{array}$ & $1 / 8 / 82$ & $\begin{array}{l}\text { Replace } 3 \text { broken tubes; Reform } \\
\text { membranes. Module used in washing } \\
\text { studies. }\end{array}$ \\
\hline 7 & $2 / 24 / 81$ & & & Continuous Service \\
\hline 6 & $3 / 3 / 81$ & $7 / 17 / 81-1$ segment & $9 / 24 / 81$ & Replace 1 broken tube. \\
\hline 5 & $3 / 16 / 81$ & $\begin{array}{l}6 / 3 / 81-1 \text { segment } \\
6 / 9 / 81-1 \text { segment } \\
6 / 18 / 81-1 \text { segment } \\
10 / 5 / 81-1 \text { segment }\end{array}$ & $9 / 18 / 81$ & Replace 3 broken tubes. \\
\hline 4 & $3 / 20 / 81$ & & & Continuous Service \\
\hline 3 & $3 / 27 / 81$ & $\begin{array}{l}5 / 19 / 81-1 \text { segment } \\
1 / 25 / 82-1 \text { segment }\end{array}$ & $9 / 3 / 81$ & Replace 1 broken tube. \\
\hline 2 & $4 / 8 / 81$ & & & Continuous Service \\
\hline 1 & $4 / 10 / 81$ & $\begin{array}{l}4 / 14 / 81-1 \text { segment } \\
4 / 22 / 81-1 \text { segment } \\
1 / 25 / 82-1 \text { segment }\end{array}$ & $9 / 15 / 81$ & Replaced 2 broken tubes. \\
\hline
\end{tabular}


from a broken tube. Only after dismantling the module following washing experiments was a tube crack found - tightly plugged by fine lint - thus plaining the lack of high flow rate indicative of a broken tube.

There is no clear evidence of membrane deterioration during the more than one year of operation. And even allowing for module $\$$, there was no indication of membrane instability for at least 10 months to date (February 1982).

\section{HF UNIT AVAILABILITY}

The hyperfiltration unit availability reflects the reliability of the components. The availability of a particular segment of the membrane area is determined by the membrane itself and by the integrity of the support structure. The availability of the hyperfiltration unit is enhanced by the design that:

(1) incorporates on 1 y $1.5 \%$ of the membrane area within one segment,

(2) provides for quick identification and location of a failure and includes the ability to bypass the single segment containing the failure, and

(3) provides for rapid replacement of the failed segment at a time scheduled for convenience.

The composite permeate from each of 10 modules is monitored in terms of flow rate and quality (qualitative color) using sight glass flow meters. In the event of a tube failure, the module can be immediately identified and bypassed (requiring the entire unit. to be off-line for less than 30 minutes). By individually checking in turn each of three groups of membrane segments within a module and then each segment of the group containing the failure, the single segment can be bypassed and the full system (minus the segment containing the failure) can be returned to service within 2 hours. (The $23 \mathrm{~m}^{3}$ capacity of the wastewater and recycle water tanks allow for over 3 hours of normal range operation with the HF system off.)

Three segments are stored as spare parts. A module can be bypassed, removed from the system, dismantled, and reassembled with a spare membrane segment and returned to the recovery system within four hours.

These procedures have been demonstrated during the course of this project. The experience with membrane availability is sumarized in Table 6 . A total of 11 tubes, of the 1,000 in the unit, have been replaced. Four additional segments require replacement at this time. We believe that the failure rate of tubes will approach zero as the initial flaws in the tubes are

eliminated. 


\section{SECTION 6}

HF UNIT PERFORMANCE

The membrane performance of the HF unit is judged in terms of quantity of wash water filtered for recycle and the quality of the water, i.e., the removal of chemicals (dyes, gums, etc.) from the filtered water, permeate. The performance of the $H F$ membranes is a function of the operating variables that produce instantaneous effects, e.g., chemical concentrations, temperature, etc., and long term effects such as foulant accumulation and membrane stability. The effective life of the $\mathrm{HF}$ unit is defined as the time interval that component failure does not impair the utility of the total unit. The effective life of a membrane is defined as the time interval that the levels of quantity and quality of water are acceptable for recycle.

In this section, membrane performance is discussed in light of a mathematical model developed to describe (predict) the quantity of water produced as a function of the wash water characteristics: chemical concentrations, temperature, pressure, and fluid velocity. The experience with foulant accumulation and membrane washing is also presented. The build up of chemicals in the wash water during a period of closed cycle operation of the dye range is presented. The replacement history of membranes and porous tubes are also presented in the discussion of membrane and HF unit life.

The plans for study and improvement of membrane performance during the continuation of this project through September, 1983 are mentioned.

\section{PERMEATE QUALITY (MEMBRANE REJECTION)}

\section{Definitions}

The quality of separation achieved by a membrane is defined by a term called "rejection." Rejection is defined as the fraction of a particular material that does not pass through the mombrane. This definition is illustrated in Figure $7(a)$ for a differential membrane element. The Single Pass membrane system arrangement is illustrated in Figure $7(b)$. In the Single Pass system the fluid progresses continuously from the feed pump to the final discharge through the concentrate control valve. The water that permeates the membrane is removed from modules, segments of the system, or as a composite whichever is most convenient. The demonstration $H$ un unit has provisions for sampling the water permeate from each of ten modules. For recycle the water from all modules is pumped into a common collection tank thus forming a composite. The rejection in terms of the composite permeate quality is related to the rejection of each membrane element integrated over the total membrane area of the system. This relationship is presented in Figure $7(b)$. The degree of conversion from wash water to permeate is called 


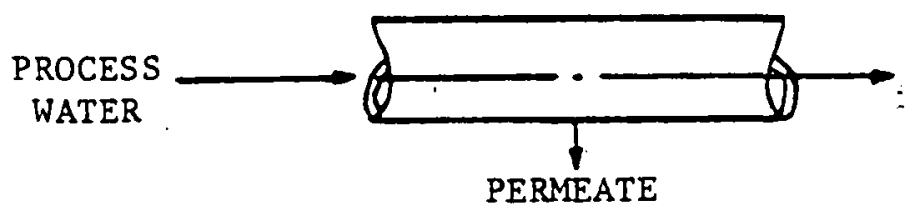

REJECTION, $\gamma=1-\frac{\text { CONCENTRATION OF MATERIAL IN THE PERMEATE }}{\text { CONCENTRATION OF MATERIAL IN THE PROCESS WATER }}$

Figure $7(\mathrm{a})$. Differential Membrane Element.
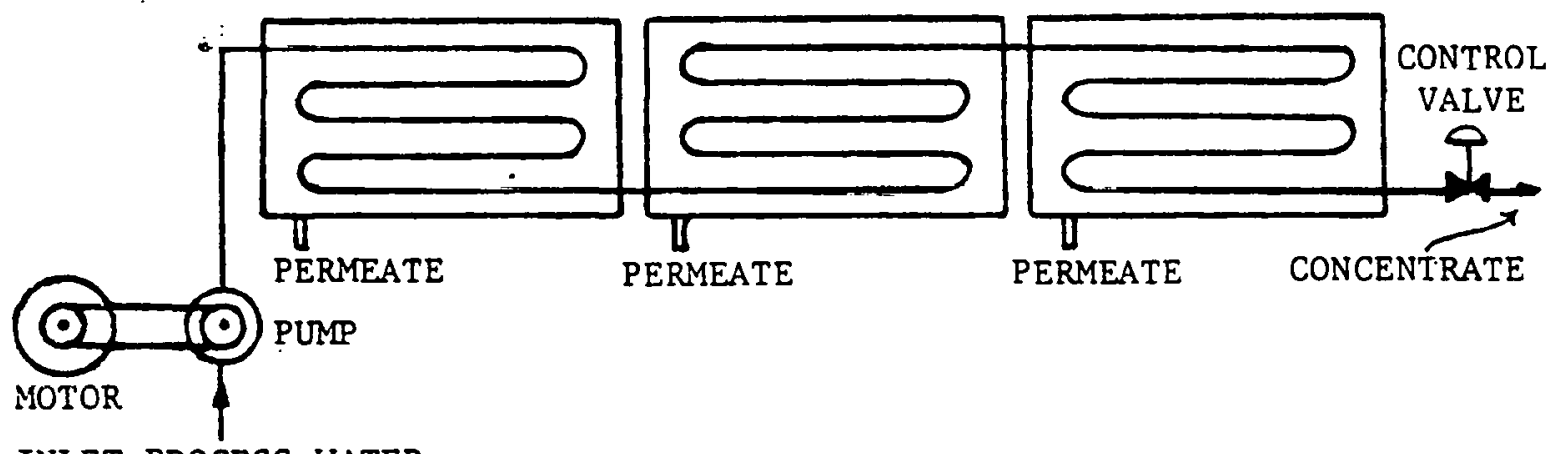

INLET PROCESS WATER

CARRE DWG. NO. 313:

$$
\begin{aligned}
& \text { RECOVERY }, R=\frac{\text { VOLUME FLOW OF PERMEATE }}{\text { VOLUNIE FLOW OF INLET PROCESS WATER }} \\
& \frac{\text { CONPOSITE PERMEATE CONCENTRATION }}{\text { INLET PROCESS WATER CONCENTRATION }} \frac{(C P)}{(C F)}=\frac{1}{R} 1-(1-R)^{1-\gamma} \\
& \frac{\text { CONCENTRATE CONCENTRATION } \cdot\left(\frac{C}{C}\right)}{\text { INLET PROCESS WATER CONCENTRAT ION }(\overline{C E})}=(1-R)^{-\gamma}
\end{aligned}
$$

Figure $7(b)$. Single Pass Membrane System Arrangement. 
"recovery," ( $R$ ). Recovery is simply the ratio of the volume of the permeate to the volume of wash water being supplied to the HF unit, Figure $7(b)$.

The material rejected by the membrane is concentrated as the wash water passes down the Single Pass system. The degree of concentration depends on the recovery as well as the rejection. This relationship is also shown in Figure $7(b)$.

\section{Stability of Membrane Rejection}

During the course of this project, samples have been collected for chemical analyses to document the membrane performance in terms of rejection. The parameter of primary interest for reuse of the permeate is the color. In Table 4 a list of selected data and results indicate that the color rejection of the membrane system has remained essentially constant throughout the course of this demonstration. Included in Table 4 are data for conductivity. The rejection of conductivity is included as an indicator of the rejection of species (e.g. salt) other than the larger organic molecules represented by the dyes, i.e. color.

\section{Build Up of Chemicals}

Closed cycle operation of the dye range raises the question of build up of chemicals in the wash water. Build up could occur because rejection is less than 100\%. The build up is limited however by the introduction into the system of fresh water. Fresh water enters with the dye pad solutions that are mixed in the drug room with plant water. This flow of water varies from about 9 liters per minute to 35 liters per minute depending on the details of a particular production lot. Of course, a corresponding amount of water is removed from the washers since the fabric is initially dry but leaves the last washer saturated containing about one kilogram of water for each kilogram of fabric.

To date, complete closed operation of the dye range has occurred only for periods of 2-4 hours duration, after which no recycle occurs for a corresponding time period while permeate is accumulated. A detailed evaluation of the chemicals introduced in the dye pad, the composition of wash water from the range, and the quality of permeate generated by the hyperfiltration unit were, however, monitored during a controlled period of complete recycle. The analysis of the results are presented in Appendix $B$. Taking into account the time lag involved from when the dye solution is deposited on the fabric to when pumped into the hyperfiltration unit, there is no accumulation of material in the wash water. There is, however, $a$ relationship between the quality of the permeate and the quantity of chemicals introduced in the dye pad. For example, during the course of the controlled recycle experiment, the concentration of dyes being used varied by 50 to 1. The concentration of dissolved solids in the permeate varied in $a$ way predicted simply by the rejection of the membrane system. Consequently it is concluded that there will be no significant build up of chemicals in the wash water. 
TABLE 4 .

Selected Membrane Performance Parameters Throughout the Course of the Demonstration

\begin{tabular}{|l|r|l|r|l|r|r|}
\hline \multirow{2}{*}{ DATE } & \multicolumn{2}{|c|}{ FEED } & \multicolumn{2}{c|}{ PERMEATE } & \multicolumn{2}{c|}{ REJECTION } \\
\cline { 2 - 7 } & CON $/ \mathrm{cm}$ & ABS & MS/COND & ABS & \multicolumn{1}{c|}{ COND } & ABS \\
\hline $6-2-81$ & 510 & 1.1 & 175 & 0.058 & $67.7 \%$ & $94.7 \%$ \\
$7-30-81$ & 740 & 0.65 & 200 & 0.0 & $73.0 \%$ & $100 \%$ \\
$8-18-81$ & 480 & 0.75 & 85 & 0.01 & $82.3 \%$ & $98.7 \%$ \\
$9-30-81$ & 360 & 0.20 & 195 & 0.015 & $46.0 \%$ & $92.5 \%$ \\
$10-9-81$ & 475 & 0.76 & 195 & 0.02 & $59.0 \%$ & $97.4 \%$ \\
$11-24-81$ & 480 & 0.96 & 200 & 0.021 & $58.3 \%$ & $97.8 \%$ \\
$12-15-81$ & 860 & 1.0 & 295 & 0.015 & $65.7 \%$ & $98.5 \%$ \\
$1-20-82$ & 250 & 0.23 & 61 & 0.012 & $75.6 \%$ & $94.8 \%$ \\
$2-19-82$ & 1250 & 2.7 & 410 & 0.031 & $67.2 \%$ & $98.9 \%$ \\
$3-2-82$ & 320 & 0.68 & 120 & 0.014 & $62.5 \%$ & $97.9 \%$ \\
\hline
\end{tabular}


A quasi-steady state condition of permeate quality with dye solution is tablished in less than 2 hours. This quasi-steady state involves a wide . riation in permeate quality but it is a variation that essentially is in equilibrium with the concentration of material having been introduced into the dye pad formulation at an appropriate interval of time preceding the generation of the permeate. Thus, it is possible for the fabric production to be sequenced in such a manner that the permeate would be unsatisfactory for recycle if a very heavy production shade were to be followed by a very light shade. The effects of production on the reuse of permeate are discussed more completely in Section 7, Recovery Process.

In summary, the membrane rejection has proven to be stable during the demonstration period, to date approximately twelve months.

\section{PERMEATE QUANTITY (MEMBRANE FLUX)}

The quantity of permeate generated by the recovery system is a function of the operating conditions at any given moment and a function of longer terms effects such as fouling, and possibly membrane modification including deterioration.

\section{Definitions}

The quantity of permeate generated is expressed as membrane flux (i.e., the volume $q$ permeate per unit of membrane area per unit of time). Common units are $\mathrm{m} / \mathrm{m}^{2} / \mathrm{day}$ or $\mathrm{m} / \mathrm{d}$. This measure of flux may further be normalized by dividing by pressure to give permeability (i.e., flux per unit of pressure, $\mathrm{m} / \mathrm{d} / \mathrm{Pa}$. )

\section{Short Term Effects}

The principle operating conditions that are known to have essentially an instantaneous effect on membrane flux are temperature, pressure, and concentration of $\mathrm{gum}^{2}$. Depending on the concentration of gum, there may also be an effect of lluid velocity. A mathematical model describing the effects of these variables on membrane flux has been developed. This model is discussed in Appendix $C$.

The measured pressure distribution is compared in Figure 8 with the calculations using the model. The model requires as input the inlet pressure and the flow rate. Experience has indicated that the membrane performance is insensitive to instantaneous values of chemical concentration but may be diminished by long term accumulative effects, e.g., fouling. 


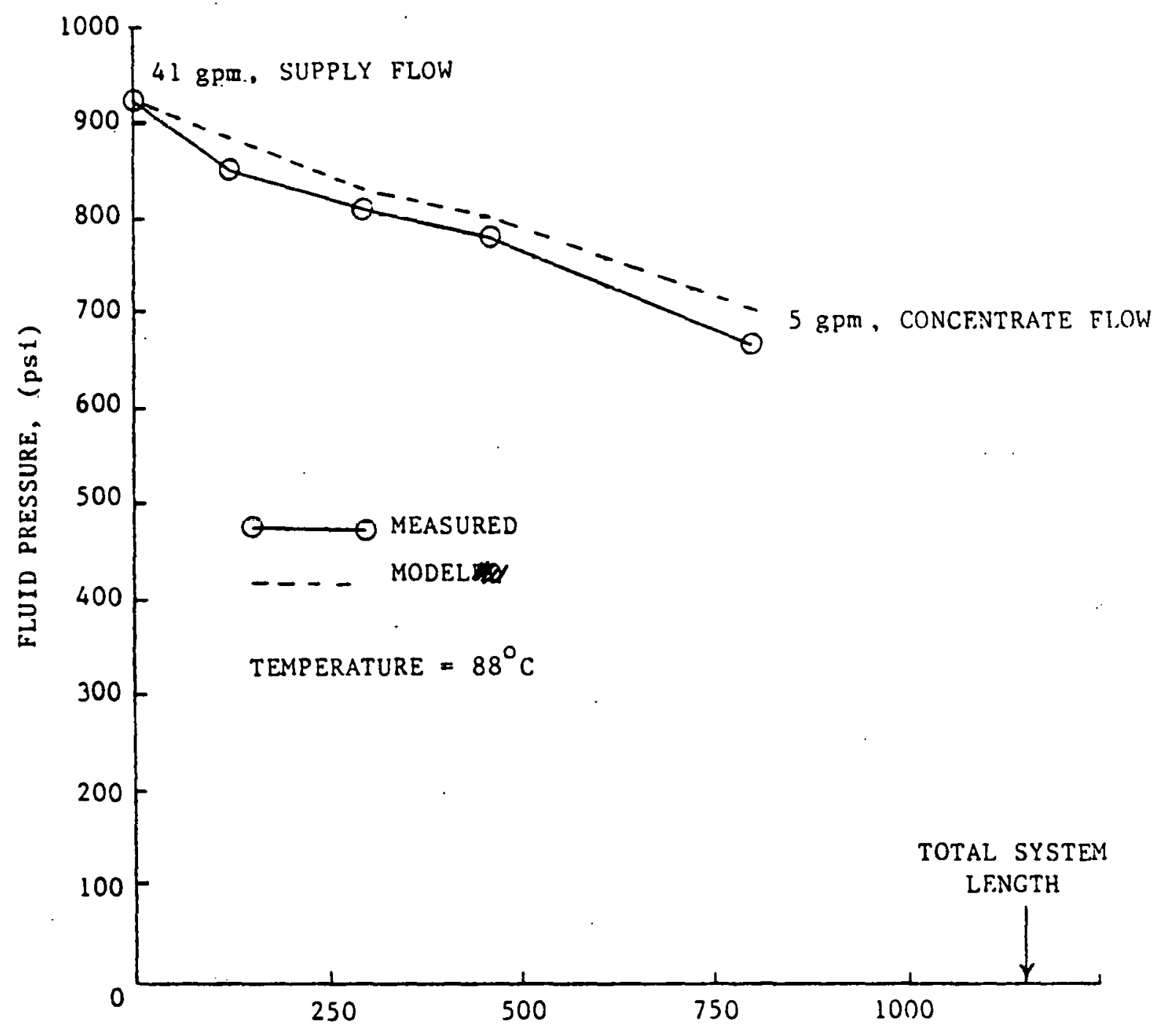

SINGLE PASS SYSTEM LENGTH TRAVERSED, (meters)

Figure $\boldsymbol{B}$. LaFrance Single Pass Hyperfiltration System Pressure Profile Modeled versus Measured. (Outlet module, $330 \mathrm{~m}$, is not installed. Total system length is 1140 meters.) 
The two major long term effects on membrane performance are the accumulation of deposited foulants and possibly membrane chemical dification, including deterioration.

\section{Membrane Fouling and Washing}

Membrane fouling is defined as a decrease in flux that is not an instantaneous reversible effect of pressure, temperature, velocity, concentration, or other controlled operating variable. Fouling is usually categorized as (1) an alteration in the membrane due to chemical reaction with the waste stream or (2) an accumulation of a deposited layer. An example of alteration in the membrane are reactions between the charged membrane and metal ions $\mathrm{Cu}++, \mathrm{Mg}++, \mathrm{Ca}++, \mathrm{Fe}+++$, etc. that commonly occur in the wash water. Reactions can also be possible with polymers. Examples of the type of deposits that may occur are:

(1) undissolved dye particles

(2) calcium carbonate, or similar insoluble compounds of the metals

(3) undissolved fraction of the guar gum which could form a carbohydrate film

(4) fine lint and other suspended solids, perhaps in combination with the gum,

(5) the insoluble reaction products of basic and direct dyes (the two major classes of dyes in use on the dye range),

(6) silicone and other oils used as anti-foam agents, and

(7) biological material that may be formed in the storage tanks.

Because the removal of foulants depends on the nature of the foulant, the washing procedures tested have been selected to attack one or more of the types of fouling potentially present. The sequence of cleaning is also important, for example an oil coating will interfere with the acid cleaning for calcium carbonate and will also interfere with enzyme removal of a carbohydrate film.

Membrane fouling: By October, 1981 the membrane system had been operated without cleaning for 100 hours at low temperature and was thus fouled. During October a great deal of attention was given to cleaning the membranes. The washing techniques employed and their results are detailed. The results are also indicated in Figure 9 and 10 where, apparent membrane permeability, based on the inlet pressure, is plotted for the period of October, 1981 through February, 1982. Figure 9 shows this information for the first seven modules of the ten module membrane system. Figure 10 shows similar information for the outlet section of the membrane recovery system. This outlet section contained at various times two modules, three modules, and one module. The exact configuration at any time is indicated in Figure 10. Examination of the two figures indicates that perhaps different phenomena are being experienced in the two portions of the membrane system. The fouling rate seems to have progressed to a greater extent and in a somewhat different manner in the first seven modules of the membrane system. The reason for the difference in the performance of the two sections of the 


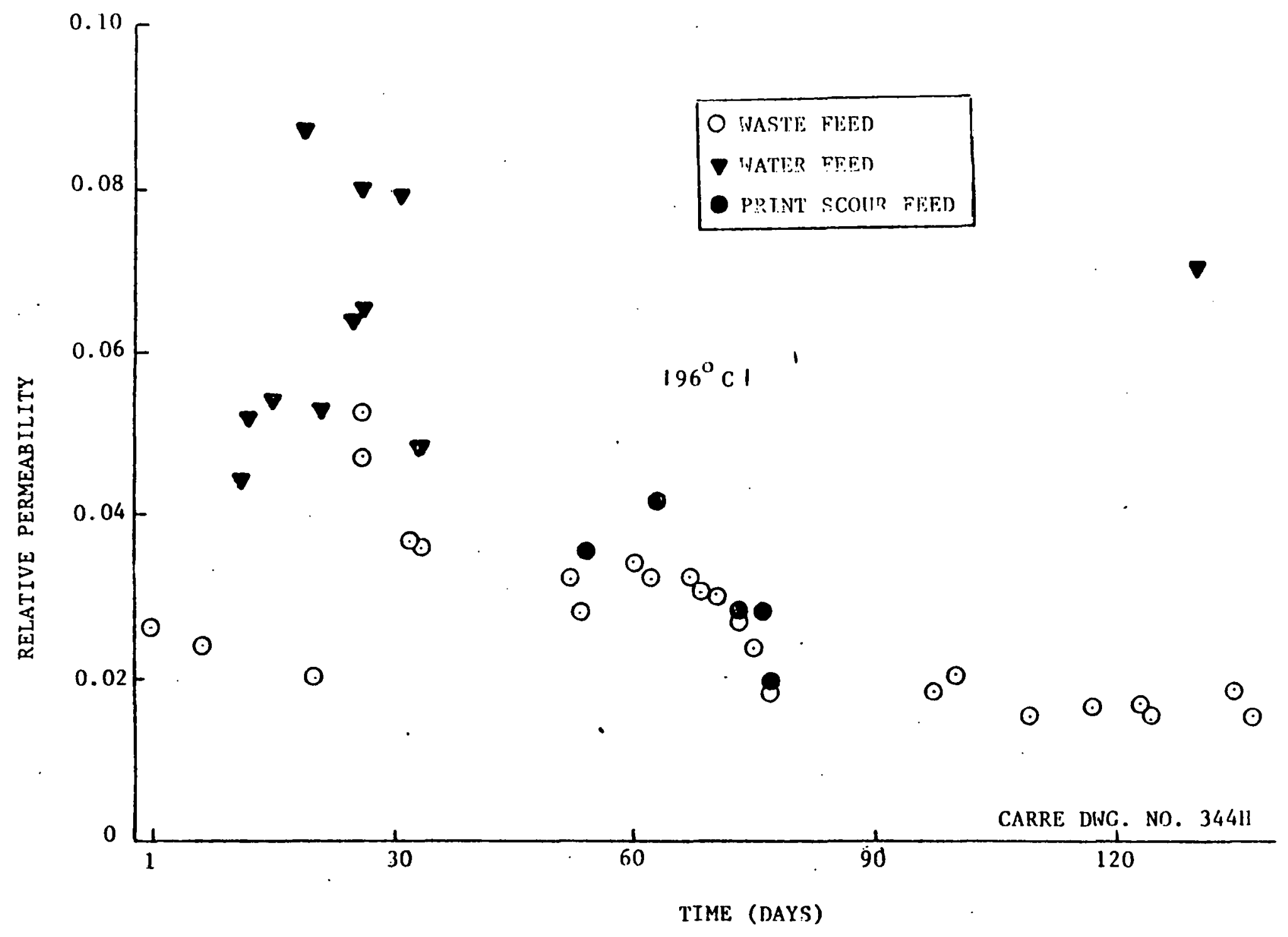

Figure 9. Relative Permeabllity versus Time for the Upstream Seven Modules 


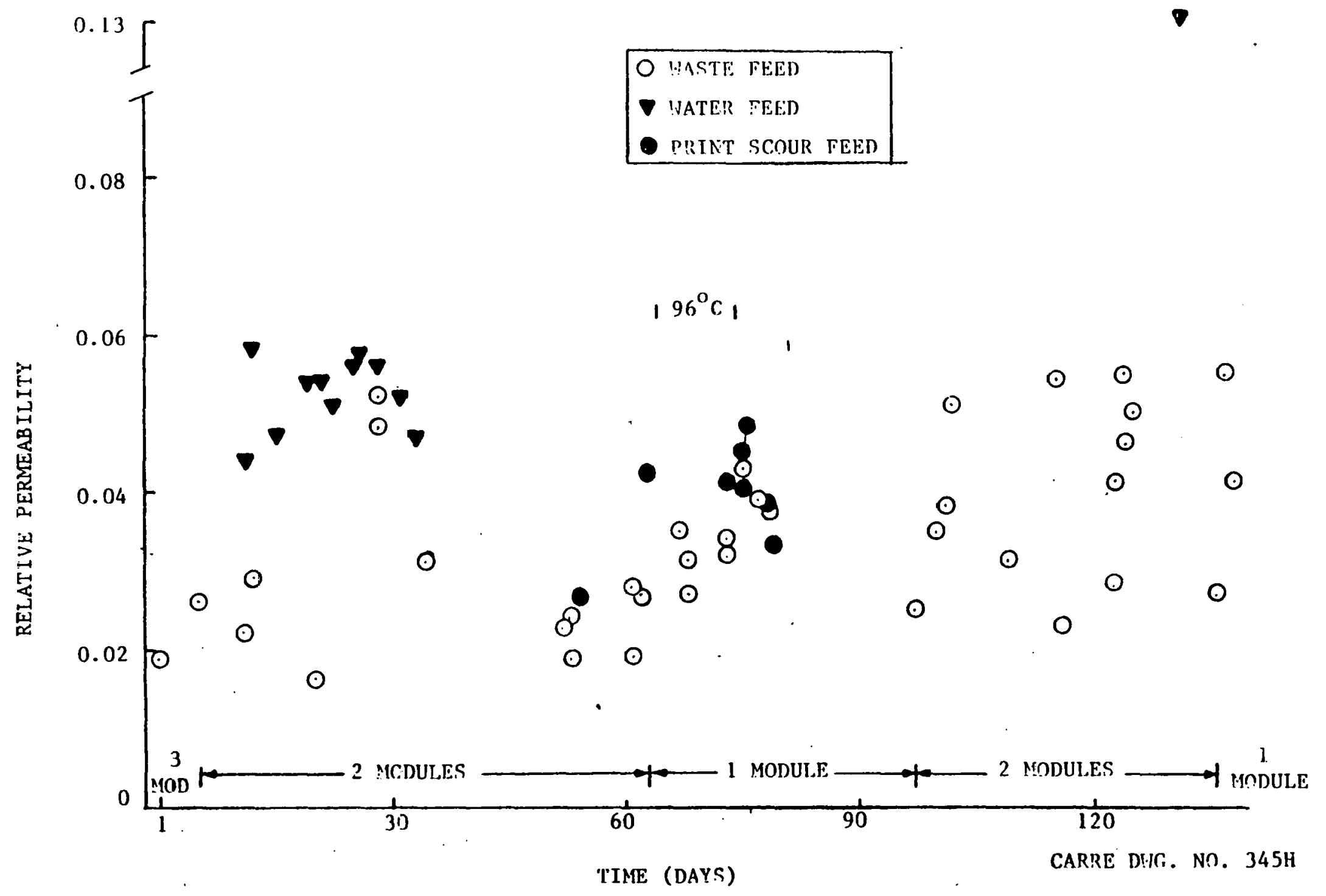

Figure 10. Relative Permeability versus Time for the Downstream Modules 
membrane system is not well understood. There are some obvious differences in operation that may be contributing factors. It is not trivial to say that le seven modules are upstream in the system and provide a large surface area -ur the possible adsorption or deposition of foulants. It is also true that the fluid velocity in this first section is lower than fluid velocity in the outlet sections of the system.

The system was designed to have lower velocities in the initial sections because pilot plant test data indicated limited velocity effects in the regions where the concentrations had not progressed extensively. Consequently, the initial sections of the membrane system were designed to have velocities in the range of 1.5 to $2 \mathrm{~m} / \mathrm{sec}$. The outlet section of the membrane system where the concentration of gum is highest, was designed to have velocities ranging up to $3 \mathrm{~m} / \mathrm{sec}$. However, as fouling progresses to the point that the membrane system is not capable of handing the full pump output, the velocity field in the inlet section of the membrane system actualiy decreases while the velocity in the outlet section is maintained constant. The outlet velocity is constant because the volume of concentrate leaving the system is controlled. Thus any fouling effects that are associated with velocity will become progressively worse in the inlet section. At the flux levels indicated in January and February, 1982, the maximum velocity entering the first portion of the membrane system had decreased to about $1 \mathrm{~m} / \mathrm{sec}$.

In the outlet section of the membrane system the velocity is dependent on the number of modules installed. With three modules in place, the velocity varies from $2.5 \mathrm{~m} / \mathrm{sec}$. at the entrance of the section to about $3 \mathrm{~m} / \mathrm{sec}$ at the exit of the membrane system (when controlled at 5 gallons per minute of concentrate). With two modules in place, the velocities are about $3.5 \mathrm{~m} / \mathrm{sec}$ to $3 \mathrm{~m} / \mathrm{sec}$. And with one module in place, the inlet velocity goes as high as $5 \mathrm{~m} / \mathrm{sec}$. While there is a lot of scatter in the data presented in Figure 10, there is clearly an increased unit output associated with the period in early December, 1981, when there was only one module in place.

After the extensive cleaning that took place in October, there was a decline in membrane performance in the outlet section corresponding very closely to that occurring in the inlet section of the system. However, in early December the performance of the outlet section of the membrane system began to improve. And even though there is a large scatter in the data, the membrane performance has remained high (more than $50 \%$ higher than the permeability on December 1) throughout the period when two modules were again subsequently introduced in the system.

In summary, the flux performance of the membrane system is not well understood. The differences in the performance of the inlet section and outlet section of the membrane system is also not well underytuod. The effects of washing are discussed in the next paragraph. The role of foulants and the effects of velocity and membrane position in the Single Pass system will be studied further during the extension period of this demonstration project. 
The recovery system is shown in Figure 1 with the dye range. The :ecovery system consists of a feed accumulator tank, pumps, hyperfiltration codules and concentrate and wash water tanks. The waste water flows by gravity from the dye range to a surge tank and is pumped to the wastewater tank. There is a period of time between each production lot for cleaning the range equipment and filling the dye pad. However, the water flow is continued during the down period to reduce the color in the water in the washers by about $30 \%$. A production lot can be treated in the hyperfiltration system as a batch containing chemicals from a single dye formulation when this knowledge of the composition is important in reuse or disposal of the chemicals.

The wash water effluent (HF supply) is usually highly colored and removal of at least $97 \%$ of the dyes is considered necessary to avoid possible staining of fabric during reuse. The auxiliary components must also be removed sufficiently to provide wash water with concentration differences suitable for effective washing of the fabric.

The HF concentrate contains dyes at concentrations much lower than those in the dye pad solution, but with comparable concentrations of the auxiliary chemicals. Based on pilot studies, reuse of the concentrates in the dye formulations is feasible with about $75 \%$ savings in auxiliary chemicals and an average of about $10-20 \%$ in dyes depending on the dye class. Effective reuse of the HF concentrate depends on the ability to add dyes to achieve hue and crocking characteristics needed in production. HF concentrate reuse can be enhanced by judicious scheduling of dyeing lots by shade and dye class and by using the experimentally determined guideline of using only $25 \%$ of auxiliary components in every reuse dye formulation. Appropriate scheduling has been initiated but is often interrupted by production demands.

Laboratory tests were conducted to evaluate reuse in preparation for the full scale demonstration. The results of these laboratory tests have been updated. These results are included in Appendix $D$ for the convenience of the reader.

PERMEATE REUSE

Wash water from all of the production processes, except bleaching, have been reused after hyperfiltration. Bleaching effluents are excluded until the $\mathrm{pH}$ adjustment can be accomplished to permit its reuse. The permeate has been used in all classes of processes performed on the range; washing of all dye classes, bleaching, and scouring.

Over one million meters of fabric have been washed or scoured with permeate. Permeate at the desired temperature is intermittently supplied to 
the range during all full scale operations. In normal operation permeate is automatically used when it is available. Plant water is automatically provided as the alternative source.

In recent weeks, with the unit operating with $80 \%$ or more of the membrane area in place, full-strength permeate has been used on $50-60 \%$ of the fabric produced. Although the $\mathrm{HF}$ unit is capable of matching the wash water requirement of the range for a period following cleaning of the membranes, its average supply of permeate has been sufficient to wash only about $60 \%$ of production.

Interruptions in the HF unit operation occur during membrane cleaning and evaluations of the $H F$ unit performance characteristics. In addition, the range operator discontinues the supply of waste water to the HF unit whenever the range wash boxes are normally emptied and refilled when a dark shade is followed by a light shade or a difficult process crossover occurs. These judgements have been included in the standard operating procedures to utilize operator experience.

This operator experience rule is conservative. In one observation period covering two weeks, the wash boxes were emptied and refilled 43 times. Despite the operating instructions (stated above), the wash water was supplied to the $\mathrm{HF}$ unit during the production of 27 of these lots. Only one was not successfully hyperfiltrated and reused. The single case of staining occurred when wash water from a lot dyed a dark shade (the formulation contained 32.5 grams per liter of basic and direct dyes) was reused on a lot dyed a light shade (the formulation contained only $0.3 \mathrm{grams}$ per liter of direct dyes). This 108:1 ratio in dye formulation concentration normally produces an even greater ratio in the dye concentrations in the wash boxes because the dye exhaustion is relatively less for the dark shades of basic/direct dyes than for the light direct shades. Such a large ratio in the dye concentration for consecutive lots is a severe test for the hyperfiltration unit where basic dye overall rejections of about $90 \%$ and direct dye overall rejections of $97 \%$ are routinely obtained. This single result combined with the successful hyperfiltration and reuse of hundreds of effluents suggest very few redyes would result if all range effluents were hyperfiltered without operator selection (See Appendix E).

\section{CONCENTRATE REUSE}

The full scale use of HF concentrates in production dye formulations has been initiated in a manner designed to minimize complications by utilizing hue and dye class in the reuse.

\section{Reuse Concept}

A substantial percentage of the production is fabric dyed to one of three hues of tan to brown. These print base dyeings normally occur in 80 piece (4,000 meter) lots. Because there are only three shades involved, concentrate reuse between these shades can be standardized using formulas 
developed in the dye laboratory. The initial efforts at full scale reuse of HF concentrate is emphasizing these three shades.

\section{aboratory Formulations}

Formulations were developed in the dye laboratory with HF concentrate generated from washing the medium and the dark shades. The laboratory procedure began by striking a fabric sample using as received HF concentrate. A strike consists of running a fabric sample in a prototype of the dye range dye pad and steamer. Striking with as received HF concentrate indicates the dye content available for reuse. HF concentrate from the medium and dark shades contain too much dye to allow formulation to the lightest shade. They could, however, be reformulated to their original shades respectively and to each other. HF concentrate from the lightest shade contains so little dye that it can be reformulated to itself and to any production shade by adding without altering the dye in the standard formulations. The reuse formulations developed in the laboratory ${ }^{2}$ indicated that only $25 \%$ of the auxiliary chemicals are needed when $\mathrm{AF}$ concentrate is used on a production basis.

\section{Full Scale Reuse}

HF concentrate from the darkest of the three brown shades was collected and reformulated to dye a 4,000 meter lot of the medium shade. Only 2,400 liters of HF concentrate was returned to the drug room so 1,600 liters of water were added to the concentrate to make the 4,000 liter volume necessary.

After the initial 4,000 liter of formulation was mixed, based on the laboratory formula, three dye additions were necessary. The initial formulation produced a strike that was too light (probably because of the 1,600 liters of water added to achieve required volume) so the first addition was made. Results after the first addition of dye were still slightly too light so the second dye addition was made. This resulted in too much orange so an additional add was required resulting in the proper shade. When the 4,000 meter lot was run on the dye range it came out slightly dark indicating too much dyes were used. No auxiliary chemicals were added to the formulation. The total amount of dyes used was $25 \%$ more than would have been required in a standard formulation (starting with plant water only). However, assuming that after the first dye add the shade would have been acceptable (based on dye house supervisor comments), a dye savings of $5 \%$ would have resulted. HF concentrate reuse will continue on a production scale among these three tan to brown shades before expanding the effort to other

shades. 
The HF concentrate stream will not be reuseable in every instance because of production schedules. Because of the high concentration of chemicals and corresponding small volume of the HF concentrate, treatment methods not generally applicable to textile wastewater may be considered. Several treatment methods that may be applicable due to the smaller volume include application to agriculture land, additional concentration by membranes followed by drying for land fill or incineration and oxidation by exposure to ozone. Cost estimates from commercial organizations for direct land application are presented in the section 9 of this report. Because land application may not be allowed, further volume reduction followed by incineration was studied as part of this project.

\section{DISPOSAL TECHNIQUE DESCRIPTION}

Discharge from the range occurs in two forms: the wash water discharged continuously and the drop from the dye pad following each production lot. The dye pad drop occurs in a time expected to allow direct addition to the corresponding HF concentrate. The combined concentrate and pad drop is of known composition and its reuse or disposal can be planned with that knowledge. This combined concentrated fluid becomes feed for a disposal system when the mixture cannot be reused in dye formulations. The waste stream is still too dilute at this point to go directly into a dryer so further concentration by membranes was studied. Permeate from this membrane separation may not be suitable for wash water because of the dye content but it can be reprocessed through the full scale recovery system. Overhead vapors from the dryer can be condensed in a feed preheater to recovery the energy and the water then recycled. Solids from the dryer can be incinerated or disposed of by some other method.

\section{DRYER TESTING}

A thin-film dryer was tested with various solutions of HF concentrate and dye pad drop mixtures in 200 liter batches. Two concentrations were tested, 4 and 6 percent total solids. A third solution contained 1.5 percent total solids and was too dilute for successful processing with the dryer test equipment. The 4 and 6 percent solutions were obtained by concentrating dye pad drops with no HF concentrate. Dye pad drops were used instead of range rinse water because 1 imited membrane area made it impractical to process the 10,000 and 14,000 liters needed to generate the 4 and 6 percent solutions respectively.

It was possible to obtain steady-state data for various flow rates and dryer operating conditions for each batch of feed tested. The dryer operating temperature was selected to equal that of standard process steam 
$\left(175^{\circ} \mathrm{C}\right)$. Data were also obtained for a steam temperature of $185^{\circ} \mathrm{C}$. Flow rates were limited by the quality of bottoms and amount of entrainment in the -rerhead vapors.

Low feed rates yield bottom products that had properties like tar in appearance and handling characteristics. The highest flow rates resulted in entrainment of feed solution into the overhead vapor flow. The point of entrainment provides an upper limit to feed flow rate. Preheating feed material to greater than 100C also caused entrainment due to flashing. Between these operating limits, bottom product varies in quality from friable powder to powder plus "tar-like" material.

The results of total solids analysis for bottom and condensed overhead vapors are listed in Table 7. Bottoms characterized as "tar-like" contained between 1 and 2 percent moisture by weight. Bottoms consisting of powder plus "tar-like" material contained between 5 and 10 percent moisture by weight. Bottoms samples consisting of only friable powder contained between 16 and 17 percent moisture by weight. This powder appears damp but retains friability even after being compressed by hand. Because the powder was easier to handle for disposal by incineration, flow rates for various sized dryers were determined to deliver bottoms with approximately 15 percent moisture. Test results indicate a optimum feed flow rate of 0.013 liters per minute per square meter for steam temperature of $175^{\circ} \mathrm{C}$ with a preheat temperature of $95 \mathrm{C}$ for 8 percent total solids feed to the dryer.

\section{MEMBRANE TESTING}

Membrane performance data was obtained with the unused concentrate from the dryer testing. For this test a combination of 1.5 and 4 percent total solids solution was concentrated with membrane equipment to 7 percent total solids. Samples were taken at specified recoveries to determine the concentration of solids in the feed and to evaluate total solids rejection.

Flux versus total solids concentration is plotted in Figure 11 . The flux declines with feed concentration. Flux versus pressure is shown in Figure 12 for several levels of concentration. The curves are typical of HF of high molecular weight solutes, Flux becomes increasingly less dependent on pressure as the pressure increases. (Velocity variation effects were not studied because the highly colored solution obscured the float in the flow meter.) Color rejection was constant at about $97 \%$.

\section{MEMBRANE/DRYER INTERFACE}

Membrane sizing can be based on an average flux for concentrating the waste stream from 2 percent to 10 percent total solids in a single pass system. With an average membrane flux of $1 \mathrm{~m} / \mathrm{d}$, the area required to deliver 2 liters per minute at 10 percent total solids from 10 liters per minute of 2 percent is approximately 12 square meters. The membrane cost is $\$ 24,000$ with about $\$ 10,000$ for pumping and controls if the additional area cannot be attached to the existing hyperfiltration unit. The dryer area required to 


\begin{tabular}{|c|c|c|c|}
\hline & Sample & Total Solids (\%) & Description \\
\hline Discillace: & $\begin{array}{r}1 D \\
2 D \\
3 D \\
4 D \\
5 D \\
6 D \\
7 D \\
8 D \\
9 D \\
10 D\end{array}$ & $\begin{array}{l}.072 \\
.054 \\
.011 \\
.060 \\
.050 \\
.030 \\
.020 \\
.035 \\
.020 \\
.055\end{array}$ & . \\
\hline Botroms: & $\begin{array}{r}2 B \\
3 B \\
4 B \\
5 B \\
6 B \\
7 B \\
8 B \\
9 B \\
10 B\end{array}$ & $\begin{array}{l}91.86 \\
85.00 \\
99.07 \\
98.64 \\
82.59 \\
82.32 \\
91.59 \\
94.25 \\
93.95\end{array}$ & $\begin{array}{l}\text { (b) } \\
\text { (a) } \\
(\text { c) } \\
\text { (c) } \\
(a) \\
(a) \\
\text { (b) } \\
\text { (b) } \\
\text { (b) }\end{array}$ \\
\hline
\end{tabular}

\footnotetext{
(a) powder

(b) powder plus "car-like" material

(c) "rar-1ike" material
} 


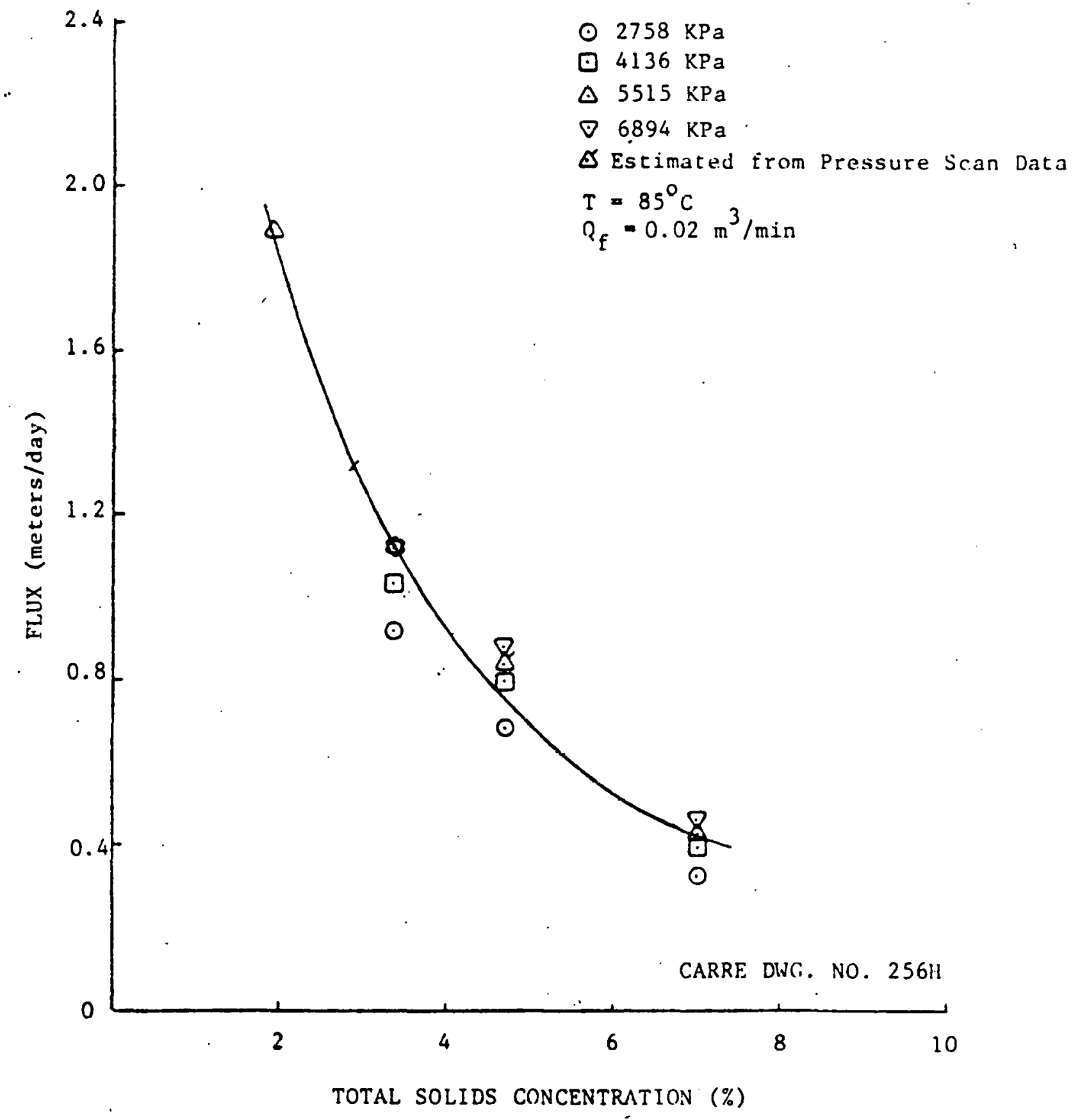

Flgure 1I... Flux versus Total Solids Concentration - Concentrate Disposal Membrane Performance 


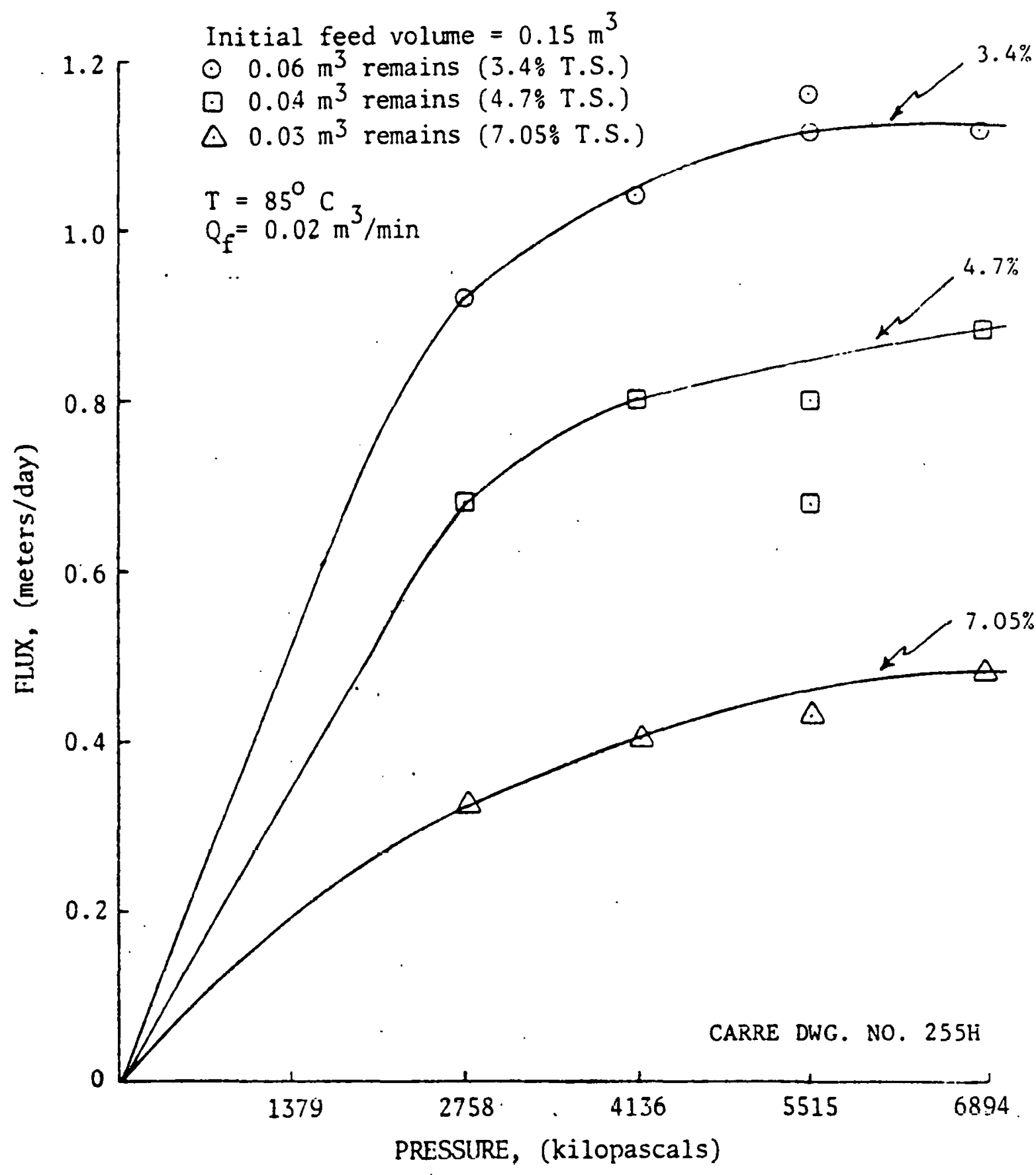

Figure 12. Flux versus Pressure - Concentrate Disposal Membrane Pertormance 
achieve 85 percent solids is 1.4 square meters. Standard dryer sizes are 1 square meter and 2 square meters. The smaller dryer should be adequate because the system can be operated as a batch process. The equipment cost commercial estimates) for the dryer is about $\$ 73,000$. An entrainment - eparator is estimated to cost $\$ 7,500$.

\section{INCINERATION TESTING}

Disposal of sludge generated from the testing with the dryer and the hyperfiltration pilot unit was investigated. A laboratory study was conducted to evaluate the incineration characteristics of the sludge, the ash volume generated by incineration, and the toxic characteristics of the sludge and the incinerated ash.

A mixture of power and "tar-like" material was evaluated. A sample of this material was dried at $105 \mathrm{C}$ for 24 hours to determine the moisture content, and a sample of the residue was ignited in a muffle furnace at $815^{\circ} \mathrm{C}$ to determine the ash content. These analyses are presented in Table 8.

The sludge ignited readily and generated a yellowish white smoke that was slightly irritating to the nose and throat. Burning the residue in open air over a flame generated a black soot probably due to incomplete combustion. The residue was fluid at incineration temperature, but solidified on cooling to a hard black solid that crumbled easily and had a sulfur-like odor. The ash was scraped from the ceramic dishes, weighed, and subjected to the extraction procedure required to determine EP toxicity . A sample of the residue before incineration was also subjected to the extraction procedure. The results of the chemical analysis of the extracts are presented in Table 8 along with the allowable concentration levels. It should be noted that dried residue from the membrane/dryer equipment remains water soluble and contains substantial amounts of dyes. Leachant from this residue would be highly colored and might cause problems in a landfill disposal application.

It was noted that the initial $\mathrm{pH}$ of the sludge extract was 5.5; the initial $\mathrm{pH}$ of the ash extract was 12.5. The sludge extract was adjusted to $\mathrm{pH}$ of 5.0 by the addition of $5 \mathrm{mls}$ of $0.5 \mathrm{~N}$ acetic acid. The addition of the maximum amount of acid recommended by the extraction procedure, $4 \mathrm{mls}$ acid/gram of solid, reduced the $\mathrm{pH}$ of the ash extract from 12.5 to $\mathrm{pH} 9.8$. During the extraction procedure, a sulfide odor was generated by the incinerated ash sample; the sulfide concentration in the extract at the conclusion of the extraction was $850 \mathrm{mg} / \mathrm{liter}$.

\section{SUMMARY}

The introduction of the $\mathrm{HF}$ concentrate to the biological waste treatment has caused no problems. There is a large dilution ( $\geq 40$ to 1 ) of the HF concentrate in the well stirred $150 \mathrm{~m}^{3}$ sump tank ahea $\bar{d}$ of the aeration basin. 
TABLE 8. RESULTS OF EP TOXICITY TESTING ON HYPERFILTRITION/ EVAPORATION SLUDGT AND INCINERATED A.SH ${ }^{3}$

\begin{tabular}{|c|c|c|c|}
\hline Contaminant & $\begin{array}{c}\text { Allowable * } \\
\text { Concentration, mg/e }\end{array}$ & $\begin{array}{c}\text { Dye Waste } \\
\text { (As Received), mg/l }\end{array}$ & $\begin{array}{l}\text { Incinerated } \\
\text { Ash, } \mathrm{mg} / \mathrm{\ell}\end{array}$ \\
\hline Arsenic & 5.0 & $<0.03$ & $<0.1$ \\
\hline Barium & 100.0 & 0.2 & 0.2 \\
\hline Cadmium & 1.0 & 0.03 & 0.10 \\
\hline Chromiun & 5.0 & 0.28 & 0.07 \\
\hline Lead & 5.0 & 0.35 & 0.77 \\
\hline Mercury & 0.2 & 0.0008 & $<0.0002$ \\
\hline Selenium & 1.0 & $<0.01$ & $<0.01$ \\
\hline Silver & 5.0 & 0.08 & 0.09 \\
\hline Endrin & 0.02 & $<0.001$ & $<0.001$ \\
\hline Lindane & $0: 4$ & $<0.001$ & $<0.001$ \\
\hline Methoxychlor & 10.0 & $<0.010$ & $<0.01$ \\
\hline Toxaphene & 0.5 & $<0.01$ & $<0.01$ \\
\hline $2,4-D$ & 10.0 & $<0.01$ & $<0.010$ \\
\hline $2,4,5-T P$ & 1.0 & $<0.01$ & $<0.01$ \\
\hline
\end{tabular}


The disposal of the HF concentrate on agricultural land is economically attractive, but may not be desirable because of potential liability. Tncineration, after appropriate drying, has been shown to be technically asible with on-site disposal of the ash. The cost of incineration with commercially available equipment is high. Smaller units designed for the small capacities of a typical textile plant might reduce the costs significantly. 
Economics of this hyperfiltration demonstration project and other hyperfiltration applications in the textile industry are considered in this chapter.

There are four elements of purpose for this chapter: (1) to present the cost and savings of this project, (2) to estimate the cost and savings for future hyperfiltration applications in the textile industry based on the data of this demonstration, (3) to evaluate the sensitivity of costs to certain process and operational variables', and (4) to discuss the economic aspects of hyperfiltration as applied to other industrial processes.

The actual capital expended for the installation of the demonstration unit is reported and examined in some detail. Because this is a demonstration project, certain costs were incurred that are greater than would normally be expected for a non-demonstration application. These include such items as recording instrumentation to allow reporting of results and engineering costs incurred through changes of scope in the demonstration project. The experience of this demonstration is used as the basis for capital cost projections for other applications.

Hyperfiltration economics are sensitive to a number of parameters; some of these will be examined. In this demonstration, the hyperfiltration recovery system was a retrofit to an existing textile plant. Therefore, waste treatment facilities were in place and only savings in waste treatment due to reduced operating cost could be counted. In the case of a new plant where a recovery system would result in a smaller waste treatment system, the reduced capital cost could be taken as a savings against the hyperfiltration system capital cost. Savings through recycle result from reduced consumption of water and reduced water treatment costs, energy conservation, and chemical recovery. Other applications may be more or less conducive to recycling of any of these constituents.

All analyses for this report are done in 1981 dollars with no direct effects of inflation.

A major emphasis for this chapter is on establishing capital and operating costs and savings information based on the demonstration. Example measures of merit are given: internal rate of return, pay out time, and return on original investment are caleulated. 
- Elements of capital cost ind operating expenses are tho the United States Environmental Protection Agency and procedure for cost analysis of pollution control operations 4 .

recommended by their standard

\section{OST DATA FOR THE DEMONSTRATION}

\section{Capital Costs Data}

Table 9 lists elements of capital costs for the recovery system. The hyperfiltration membrane modules, their support structures, and the high pressure pumping and its associated controls including a $\mathrm{pH}$ control system were provided by a single equipment vendor. Both the control panel and a monitoring or display panel were provided independently by another vendor. Engineering was provided by a local architectural/engineering firm. All other items were provided by a prime contractor with the exception of heat exchangers which were a retrofit to the recovery system provided by a second contractor. All other direct costs were taken from invoices submitted by the prime contractor. Freight, sales tax and construction overhead were also taken from these invoices as was the contractor fee.

The total recovery system plant cost $\$ 558,000$. This is the total depreciable investment since neither interest nor start-up costs were capitalized or provided for. No value was placed on the space required for the hyperfiltration unit and recovery system.

Because this is a demonstration unit, certain of these capital costs were incurred because of special reporting requirements, delays and changes of scope in the project, and engineering design changes. Table 10 is a revision of Table 9 in which some of the capital costs have been changed to remove the demonotration project effects and to reflect, in the case of the hyperfiltration unit, a 1981 price.

The following are comments on Table 10 and are listed by number (superscript) shown in the table.

1. The revised hyperfiltration unit price reflects an updated 1981 quotation from the vendor. The 1981 price also includes a feed booster pump and a $0.75 \mathrm{~m}^{3}$ stainless steel wash tank.

2. While the control panel requirements did not change, the monitoring (display) panel was eliminated from Table 10. The panel housed instruments (not included in the panel price) that are necessary only for the special data collection and reporting of the demonstration project. 
1. Purchased Equipment Cost for each major plant item
a. Hyperfiltration Unit
$\$ 244,000$
b. Control Panel
12,000
c. Monitoring Panel
10,000
d. Heat Exchanger
10,000
e. Other Items
TOTAL $\$ 313,000$

2. Direct Field Materials
a. Piping
b. Instrumentation
c. Electrical
d. Excavation
e. Insulation
f. Equipment Rental

42,000

32,000

37,000

12,000

10,000

5,000

3. Direct Field Labor

4. Adjunct Facilities

TOTAL $\$ 138,000$

$$
30,000
$$

TOTAL DIRECT COSTS

$\$ 491,000$

5. Indirect Costs
a. Frelght
b. Insurance
c. Sales tax
d. Construction $\mathrm{O} . \mathrm{H}$.
e. Engineering

TOTAL $\$ 50,000$

6. Contractor's Fee

17,000

TOTAL PLANT COSTS

$\$ 558,000$

7. Interest during construction if capitalized

$-0-$

8. Start-up cost, if capitalized -0-

TOTAI DEPRECIABLE INVESTMENT

$\$ 558,000$

9. Land $-0$

10. Working Capital

$-0$

TOTAL CAPITAL INVESTMENT

$\$ 558,000$ 
Table 10. Capital Costs for Subsequent Hyperfiltration Applications Based on this Demonstration

1. Purchased Equipment Costs for Major Plant Item
a. Hyperfiltration Unit $\$ \$ 300,000$
b. Control Panel
c. Monttoring Panel ${ }^{2}$
12,000
$-0-$
d. Heat Exchanger
10,000
e. Other Items ${ }^{3}$
(pumps, tanks, etc.)
14,000
TOTAL $\$ 336,000$

2. Direct Field Materials
a. Piping 34
b. Instrumentation 45
c. Electrical ${ }^{6}$
d. Excavation?
e. Insulation
f. Equipment Rental

$$
\begin{gathered}
28,000 \\
10,000 \\
25,000 \\
-0- \\
10,000 \\
5,000
\end{gathered}
$$

TOTAL $\$ 78,000$

3. Direct Field Labor

30,000

4. Adfunct Facilities

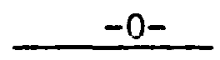

TOTAL DIRECT COSTS

$\$ 444,000$

5. Indirect Costs
a. Freight ${ }^{8}$
b. Insurance ${ }^{8}$
c. Sales $\operatorname{tax}^{8}$
d. Construction O.H. ${ }^{9}$
e. Engineering 10

1,500

1,500

- 3,000

7,000

15,000

TOTAL $\$ 28,000$

6. Contractor's Fee ${ }^{11}$
12,000

TOTAL PLANT COSTS

$\$ 484,000$

7. Interest during construction, if capitalized

$-0-$

8. Start-up Costs, if capitalized -0-

TOTAL DEPRECIABLE INVESTMENT

$\$ 484,000$

9. Land -0-

10. Working Capital -0-

TOTAL CAPITAL INVESTMENT $\$ 484,000$

* superscripts refer to items in text describing changes for Table 9 
3. Because the decisiot .o locate the recovery system i..sige the plant was a mid-project change, two major cost items can be remowed from the "other items" category. These are $\$ 17,000$ for the external structure and $\$ 6,000$ required to modify existing tanks so that they would fit through the plant doors.

4. Two items were eliminated from the piping cost. One was a $\$ 6,000$ wash tank now included in the cost of the hyperfiltration unit; the other was $\$ 8,000$ in piping changes associated with the decision to locate inside plant.

5. $\$ 18,000$ for instruments in the monitoring (display) panel were eliminated. Additionally the $\$ 4,000$ cost incurred as restocking charges for instruments returned when the design was changed to eliminate a recovery system for the fix chemicals was eliminated.

6. A $\$ 12,000$ cost to install the monitoring (display) panel was eliminated.

7. Excavation and foundation rework costs of $\$ 12,000$ are eliminated. (The decision to move the hyperfiltration unit inside the plant was made when, following excavation, it was discovered that the soil foundation would not support the recovery system).

8. The indirect cost reductions associated with the direct costs items are estimated.

9. $\$ 4,000$ in construction overhead is deleted based on $61 / 2 \%$ of $\$ 58,000$ in direct cost deletions.

10. Additional engineering costs totaling $\$ 15,000$ above the bid price were deleted. These costs were incurred due to the project changes previously mentioned.

11. The $\$ 5,000$ reduction in the contractor fee is due to the previously sumarized reduction in direct and indirect cost.

The revised capital cost, Table 10, is $\$ 484,000$. The cost for equipment, other than the hyperfiltration equipment, is $\$ 184,000$ or $60 \%$ of the cost of the hyperfiltration equipment. This number is consistent with CPI estimates and with published installation costs from the vendor of the demonstration unit, hyperfiltration unit and other hyperfiltration. vendors 4 . 
Table 10 will be used as tîie -apital cost basis for the remainder of this report.

^nnual Operating Expenses and Savings

The demonstration phase of the project is presently in progress. While capital costs are firmly established, data on annual operating expenses and savings are presently being accumulated with preliminary results available. In particular, reuse of chemicals will be further developed during the extension of this project to September 1983. The operating costs for maintenance and membrane replacement will also continue to be documented during this extended project period. At this writing the hyperfiltration system operates automatically on a full time basis. Daytime operation is frequently interrupted to carry out studies on membrane cleaning and other aspects of operation aimed at optimizing the recovery. Studies are also carried out on a longer term at other than standard operating conditions; this adversely affects the impact of recycle. Concentrate reuse techniques have been developed in the laboratory. Full scale techniques are presently being developed. Concentrate reuse trials have been successfully run but none in sufficient quantities to significantly affect savings.

The demonstration period has been extended for 18 months during which additional data on savings and operating expenses will be collected. Annual expense and savings data presented here incorporate all data available to date. Where insufficient data exists to document a cost or savings, data to date are extrapolated to obtain an annual figure.

Operating Costs--

Table 11 summarizes the annual operating expenses for the demonstration. The cost categories set forth by the Environmental Protection Agency Standard Procedures for Cost Analysis are used.

There are no raw materials required for this operation. Direct labor has been provided under the demonstration grant through one part-time technician at the site. It is estimated that one-half time is devoted to unit operation and data collection. Another one-quarter time is devoted to unit maintenance. Additional recovery unit operation is done by dye range operators via the recovery unit control panel which is adjacent to their work station. No additional manpower was required for the recovery system operation.

Maintenance material costs are taken from a maintenance log book kept by the on-site technician. The majority of the maintenance labor is provided by the on-site technician. Based on experience to date, it is estimated that an additional $\$ 2,000$ in direct labor is needed for maintenance. Sixteen percent 
TABLE 11 .

ANNUAL OPERATING EXPENSE FOR DEMONSTRATION

1. Raw Materials

2. Processing Expenses

$\begin{array}{lr}\text { Operating } & \\ \text { Direct Labor } & \$ 8,000 \\ \text { Direct Supervision } & \\ \text { Maintenace Labor } & 2,000 \\ \text { Maintenance Material } & 2,000 \\ \text { Operating Supplies } & 3,100 \\ \text { Labor Additives at 16\% } & 1,600 \\ \text { Steam } & 6,000 \\ \text { Electricity } & 15,000 \\ \text { Concentrate Treatment \& Disposal } & 20,000 \\ \text { Membrane Replacement } & \end{array}$

3. Plant Overhead ${ }^{1}$

Control Laboratory

Engineering

Plant Overhead at $88 \%$ of labor $\quad 8,800$

Other

4. Fixed Charges

Insurance

2,500

2,500

Royalty

71,500

5. General Expense

Net Annual Operating Expenses

$\$ 71,500$

6. Annual Depreciation

48,400

Total Annual Operating Expenses

$\$ 119,900$

lstralght line 10 years 
'of the direct labor cost are abor additives. Electricity" a equired to run the hyperfiltration system is metered. The primary user of electricity is the high pressure pump for the hyperfiltration system. Additional electrical power is used for small centrifugal pumps in the pipe and tank system and to the power control panels. Electricity consumption costs are based on the eek ending 12/21/81 during which 4200 kilowatts of power were used. At 50 weeks/year and $\$ 0.028$ per $\mathrm{KWH}$, the annual cost is $\$ 5,880$.

The concentrate disposal cost item is based on estimates for hauling for use on agricultural land. This number assumes that no concentrate is reused. Significant use of concentrate would lower the concentrate disposal cost.

Operation of the hyperfiltration system for more than one year and observation of the membrane replacement rate required during that period allowed the membrane system supplier to offer a $\$ 20,000$ per year service contract for membrane replacement during the project extension.

Concentrate reuse techniques developed and tested to date for concentrate reuse indicate that reformulating the concentrate for subsequent dyeings involves no more labor than the standard color matching technique now employed for new and standard dyeing. Therefore, no additional laboratory expenses are included. Plant overhead is taken as $17 \%$ of direct costs. Insurance, property tax, and overhead costs figures are based on capital costs and reflect the current percentages.

Annual depreciation is calculated using a ten year, straightline method.

Savings--

Potential savings occur in three main areas: savings of dyes and chemicals occur through concentrate reuse; water and waste treatment costs are reduced when process water is returned to the dye range; and energy is saved when hot water from the dye range is recycled at full process temperature thus avoiding the need to heat plant water. Boiler feed chemicals are saved with energy savings because make-up water to the boiler is reduced. Table 12 presents a summary of annual savings.

Savings possible through reuse of dyes and chemicals is $\$ 130,000$ a year. At present, the concentrate reuse program is just getting under way. Full scale trials have been run with three shades which make up about $20 \%$ of production (based on an analysis of production between October and December of 1981). Actual savings are calculated by comparing dye and auxiliary chemical formula sheets, with the derived formula sheets using HF concentrate. Chemicals costs are based on actual invoice cost for 1981. The 
Table 12.

\title{
HYPERFILTRATION/DYE RANGE \\ ENERGY AND WATER USE SUMMARY \\ WEEK ENDING MIDNIGUT \\ $12 / 21 / 81$
}

\begin{abstract}
ENERGY
ENERGY REQUIRED................299 MILLION BTU .....................

STEAM SUPPLIED TO WASHER...........135 MILLION BTU ..........14274 MEGA JOULES

STEAM SUPPLIED TO HEAT EXCHANGER...... 37 MILLION BTU .... 3897 MEGA JOULES

SAVINGS (REQUIRED-SUPPLIED)......... 127 MILLION BTU ........13482 MEGA JOULES
\end{abstract}

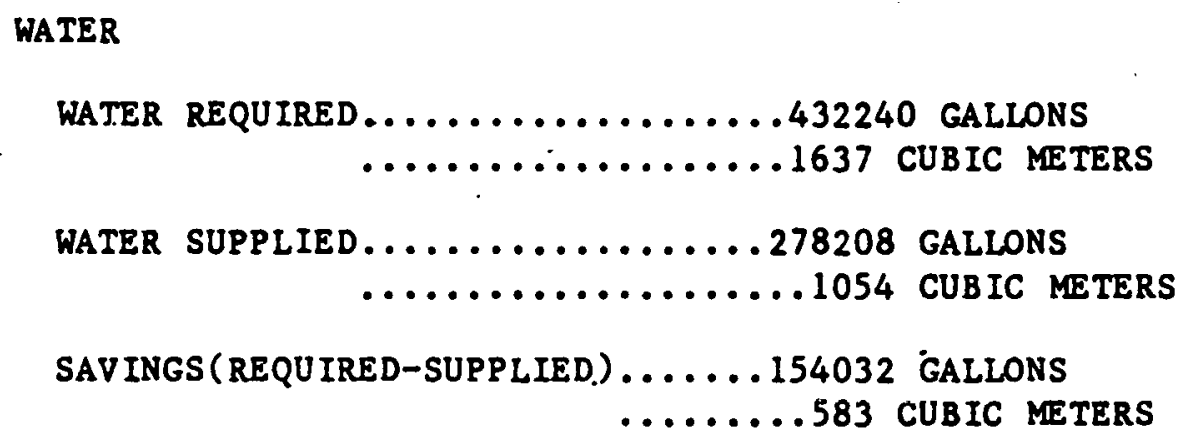

CHEMICALS 
per meter savings is then al ied to the projected producti of the three shades in the year 1982. Trials to date have shown that approximately $30 \%$ of the concentrate derived from these dye lots will not be able to be reused because of scheduling and other production difficulties. When this is taken into account the savings for these three shades is $\$ 24,000$ per year.

Energy savings are taken from the data from instruments provided to monitor flows and temperatures throughout the recovery system. Temperature and flow information from strip charts is examined and integrated on a weekly basis to determine the actual savings. The weekly energy saving varies widely at present, due to start-up and operation of the unit at off-standard conditions for experimental reasons. Table 13 is the computer output showing energy savings for the week ending December 21, 1981. This week represents a typical weekly energy saving at this time. Using the 1981 average energy cost for La France of $\$ 7.15$ per million BTU's (as steam), and projecting 50 weeks per year operation, the annual savings in energy is $6300 \mathrm{M}$ Joules. The potential energy savings from the dye range, based on range flow rates and average plant water temperature, is approximately 18,000 M Joules per year. As the demonstration continues the energy savings will more nearly approach the maximum of $\$ 125,000$ per year. Because less steam is used, boiler feed chemical savings of $\$ 3,000$ per year can also be approached.

Table 13 also presents the total water savings. The operating cost savings for water from the on-site treatment plant is $0.116 / \mathrm{m}^{3}$. The indicated water recycle results in a savings of $\$ 3,400$ per year. The operating savings for the reduced flow to the water treatment is $\$ 0.12 / \mathrm{m}^{3}$ which results in an annual savings of $\$ 3,500$. As the amount of use increases the two savings will approach $\$ 20,000 /$ year.

It is assumed that all fixed charges are unaffected by the savings . There is no change in annual depreciation. Therefore, the total annual savings for demonstration, at present, is $\$ 90,000$. This represents only $30 \%$ of the total projected savings possible through recovery. As the demonstration progresses, and concentrate reuse is more fully implemented, the savings will more nearly approach the potential of $\$ 275,000 / y r$.

\section{Data Quality}

The costs and savings data used in this report represent the present situation as closely as possible. Since actual invoices are used, capital cost information is correct. Because expenses were incurred in this demonstration project that would not normally exist in subsequent applications, a more representative capital cost is established in Table 10. Annual operating expenses were collected from plant records and operator logs. Operating techniques and procedures are still being developed so these expenses are subject to revision as more data is compiled during the extension of this project. Indirect costs are based on current plant procedures. 
1. Processing Expenses

Direct Labor
Direct Supervision
Mafntenance Labor
Maintenance Material
Dyes and Chemcials
Labor Additivies
Steam
Water
Effluent Treatment \& Disposal
Boiler Chemicals

2. Plant Overhead

Control Laboratory

Englneering

Plant Overhead

Other

$$
\begin{array}{r}
-0- \\
-0- \\
-0- \\
-0- \\
\$ 24,000 \\
-0- \\
45,400 \\
3,400 \\
3,500 \\
1,000 \\
\hline
\end{array}
$$

$\$ 77,000$

$\$ 90,000$

3. Fixed Charges

Insurance

Property tax

Royalty

$$
\begin{aligned}
& -0- \\
& -0- \\
& -0-
\end{aligned}
$$

$\$ 90,000$

4. General Expense

Total Annual Operating Savings
$\$ 90,000$ 
it

Savings are estimated $f($. operating logs and data from _-rip charts. As operating techniques develop further, on stream factors will increase and savings

wi 11 accrue

at

a

faster

rate. 
Table 14 .

Sumary of Factors Affecting Costs and Savings

for Textiles

Costs-Equipment: $250 \mathrm{~m}^{3} /$ day

Bas is: $\$ 300,000$ Hyperfiltration

$\$ 184,000$ Installation

1. Hyperfiltration system cost varies inversely with membrane flux.

2. Complexity of system external to hyperfiltration system affects cost.

3. In areas where water is in short supply or discharges are limited, recycle can enable plant expansion.

4. Reuse of hazardous material will reduce disposal costs.

5. The scale factors for the hyperfiltration system is nearly linear. Auxiliary system scale up factor may be taken as $0.6-0.7$ *

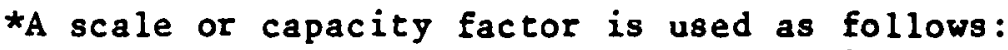

New Cost $=01 \mathrm{~d}$ Cost $\times \frac{\text { [Capacity of New] Scale factor] }}{\text { [Capacity of }}$

[Capacity of Old]

Savings -

Engineering: $\$ 125,000 /$ year

$75,000 \mathrm{~m} / \mathrm{yr}$ at $55^{\circ} \mathrm{C}$ temperature difference

1. Hyperfiltration is not a good alternative to heat exchangers for heat recovery only.

2. Savings are proportional to the difference between process and tap water temperatures.

Water: $\$ 8,000$

$$
75,000 \mathrm{~m}^{3} / \mathrm{yr} \text { e } \$ 0.16 / \mathrm{m}^{3} \text {. }
$$

1. No significant problems encountered in reuse of $95 \%$ of water.

2. Savings vary with local water costs.

Waste Treatment: $\$ 9,200$

$$
75,000 \mathrm{~m}^{3} / \mathrm{yr} \text { 巳 } \$ 0.12 / \mathrm{m}^{3} \text {. }
$$

1. Only treatment plant operation savings are available for existing direct dischargers. For indirect dischargers monthly user charges may be reduced.

2. New plant, direct dischargers, can save full BAT costs for recycle costs.

3. Existing direct dischargers save a proportional part of costs for equipment upgrading. 
4. Indirect Dischargers maý 5 may not save direct treatmen sharges.

5. Recycle of hazardous material can save disposal costs.

Material: $\$ 130,000$

Reuse of $2 / 3$ of concentrate at $\$ 0.33 /$ ititer

... Cannot be done at all plants

2. Has been done on limited production basis at La France.

\section{FACTORS WHICH INFLUENCE COSTS AND SAVINGS}

Economics of recovery depend on specific situations which vary widely from plant to plant. Table 13 summarizes the major factors which influence hyperfiltration costs and savings.

Hyperfiltration membrane costs vary inversely with membrane flux (volume productivity per unit area). Since flux values are specific for each process stream and depend on the characteristics of the process water being filtered individual tests performed for each application are required to determine membrane flux. In this demonstration membrane flux is largely controlled by the concentration of a thickening agent used in the dye pad formula and the membrane fouling.

While membrane system costs are largely determined by membrane flux, a significant portion of the capital cost is represented by auxiliary equipment. The auxiliary system and installation represented $40 \%$ of the total capital cost of the demonstration. Each recovery application will heve its own specific auxiliary system requirements and the complexity can vary widely from plant to plant. The dyeing operation is intermittant with significant down time between production lots. It was therefore desirable to incorporate large holding tanks and a complex control system to allow the hyperfiltration unit to operate in a steady fashion. In a more continuous operation the auxiliary system complexity can be reduced according to the economics and consequences of down time.

Recycle in areas where water is in short supply or plant discharges are restricted, may permit plant expansion. If discharge is limited because of hazardous materials, recycle of the hazardous material becomes particularly attractive. For instance, hyperfiltration is presently being used to filter contaminates from strong caustic solutions in a textile preparation process. This filtering allows the caustic to be reused in the process rather than discharged.

Energy savings:are proportional to the difference between the process and the supply water temperatures. While for hot process effluents, the savings due to energy recovery are significant, hyperfiltration is not a good alternative to heat exchangers for heat recovery alone. Hyperfiltration is an economically atrractive technology when water, waste treatment, and 


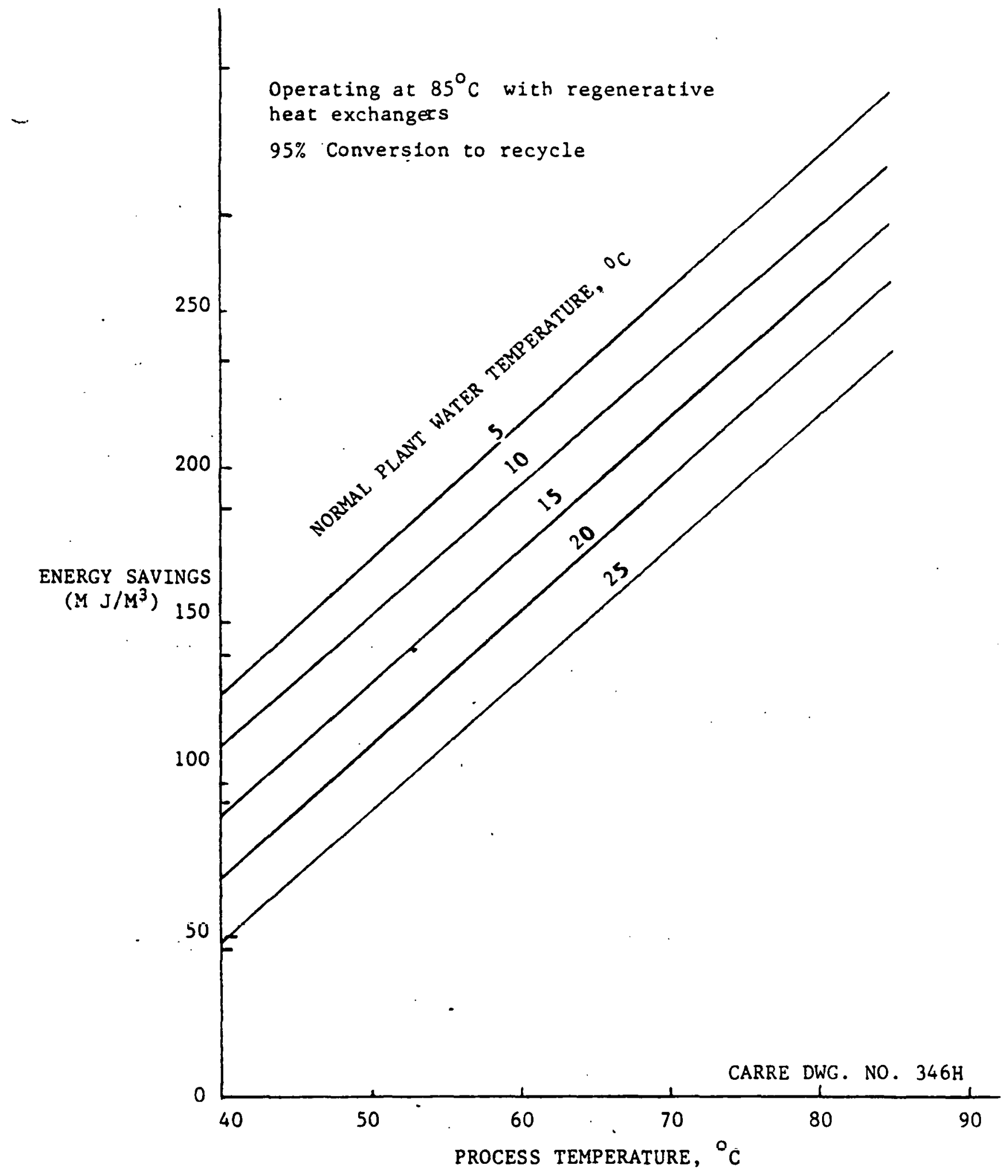

Figure 13. Energy Savings per Volume Processed versus Process Temperature for High Temperature Recovery of Hot Water. 
thaterals recovery are combi l with energy recovery. $P$ icularly since the cost of hyperfiltration is reduced by higher fluxes achieved at higher temperatures, hyperfiltration is ideally suited for recycle of hot water. Figure 12 shows the influence of process temperature on energy savings for a system operating similarly to the demonstration unit. It is assumed that egenerative heat exhangers are used to allow the hyperfiltration unit to perate at $85 \mathrm{C}$. It is also assumed that energy added to the concentrate is lost. Savings depend on the plant water temperature since this influences the increment of heating that would have to be added without recovery. The plant water temperatures shown represent extremes of summer and winter operation. Potential savings vary by a factor of five between $40 \mathrm{C}$ process temperature and $85 \mathrm{C}$ process temperature.

Savings through reduced water and waste treatment can vary widely depending on specific situations. For this demonstration water and waste treatment costs are minimal, therefore savings are minimal. Because the demonstration is a retrofit of recovery to an existing direct discharger, only treatment plant operational savings (excluding labor) are be counted. If treatment plant upgrading is necessary, then capital savings can be taken for the reduced upgrade cost. New plants who must construct new, best available technology (BAT) treatment facilities can credit the reduced treatment facility cost against the cost of the recovery system. Indirect dischargers may or may not save direct treatment cost. If fair-share costs are assessed against indirect dischargers for upgrade of municipal or regional treatment systems, then these charges are reduced by recovery.

Material recovery potential varies widely from process to process. To implement material recovery, a development program may have to be undertaken for new recovery applications. The economics of the development program depend on the value of the recovered material. While the potential value of the recovered chemicals at demonstration site is about $\$ 0.005 / 1 i t e r$, the value for other applications (for instance textile size recovery, or caustic recovery) may approach $\$ 0.025 / 1$ iter.

Since the hyperfiltration membrane system is modular in nature, capital cost varies nearly linear with system size. (See Table 13 footnotes). The installation and auxiliary system costs can be scaled up using a scale factor of 0.6 to 0.7 . Since savings are directly proportional to flow rates, economics improve with larger systems.

\section{MEASURES OF MERIT}

Internal rate of return, payout time, and return on original investment are calculated in this section using standard techniques ${ }^{4}$. Example calculations are given in Appendix F. For these calculations an income tax of $46 \%$ is assumed. While more rapid depreciation techniques are available, a ten-year straight line depreciation method is used.

Figure 14 shows the variation for the three measures of merit with savings for the demonstration system. Potential annual savings total 


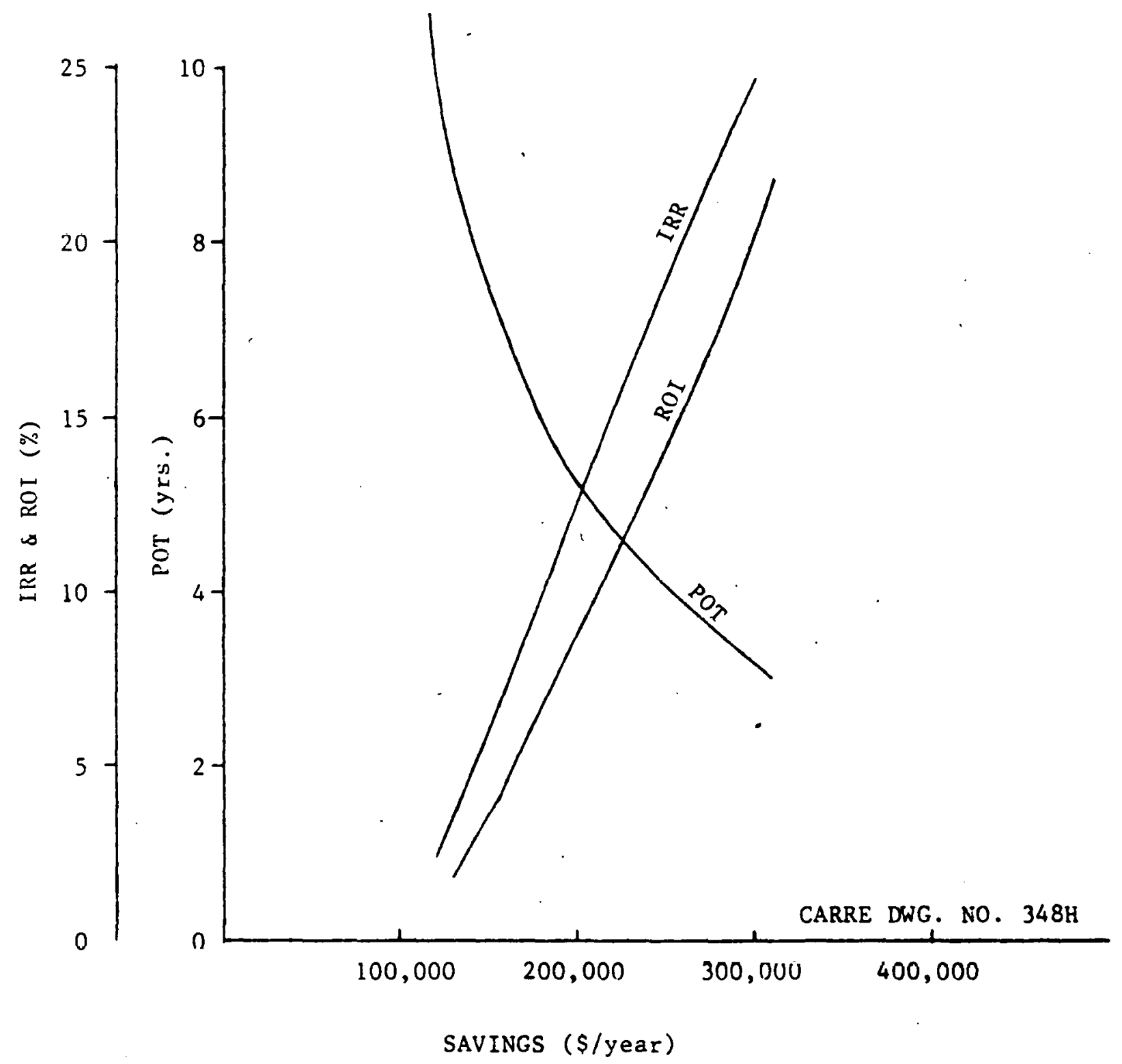

Figure 14. Payout Time (POT), Internal Rate of Return (IRR), and Return. on Original Investment (ROI) versus Savings for the Lafrance Recovery System. 
$\therefore 3$

approximately $\$ 275,000$ which rould represent a payout time wetween 3 and 4 years, a return on original investment of $15-20 \%$, and an internal rate of return on 20-30\%. Presently the system is operating at approximately the break even point.

Figure 15 shows the effect of changes in flux on the overall measures of merit for the recovery system. The savings were assumed constant and the effects of capital cost changes on the measures of merit are given. 
$\therefore: x$

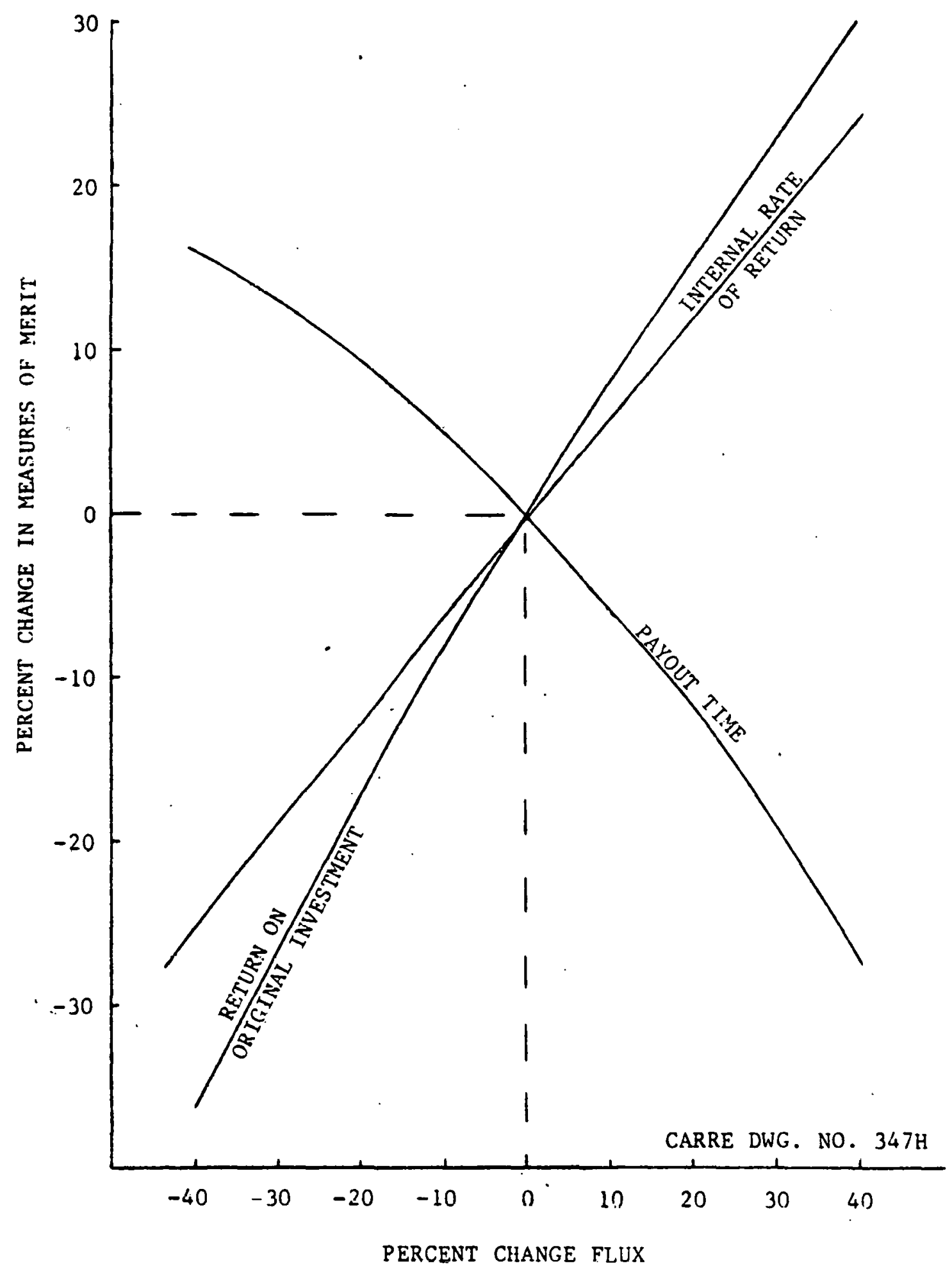

Figure 15. Effect of Flux on Measures of Merit for the Lafrance Recovery System. 


\section{RE FERENCES}

1. Brandon, C. A. and J. L. Gaddis, Full-scale Demonstration of Hyperfiltration for Closed-Cycle Textile Dyeing Facility. Desalination, 23: $19-28,1977$.

2. Brandon, C. A. Closed-Cycle Textile Dyeing: Full-scale Hyperfiltration Demonstration (Design). EPA-600/2-80-055, U. S. Environmental Protection Agency, Washington, D. C. 1980. 91 pp.

3. Federal Register, Vol. 45, No. 98, Monday, May 19, 1980, p. 33122.

4. Uh1, Vincent w. A Standard Procedure for Cost Analys is of Pollution Control Operations, Vol 1 and 2, EPA-600/8-79-018a and b, U. S.

Environmental Protection Agency, Research Triangle Park, N. C., 62 pp. and $150 \mathrm{pp}$. 